\title{
An Adaptive State Machine Based Energy Management Strategy for a Multi-Stack Fuel Cell Hybrid Electric Vehicle
}

\author{
Alvaro Macias, Student Member, IEEE, Mohsen Kandidayeni, Student Member, IEEE, Loïc Boulon, \\ Senior Member, IEEE, Hicham Chaoui, Senior Member, IEEE
}

\begin{abstract}
This paper aims at designing an online energy management strategy (EMS) for a multi-stack fuel cell hybrid electric vehicle (FCHEV) to enhance the fuel economy as well as the fuel cell stacks (FCSs) lifetime. In this respect, a two-layer strategy is proposed to share the power among four FCSs and a battery pack. The first layer (local to each FCS) is held solely responsible for constantly determining the real maximum power and efficiency of each stack since the operating conditions variation and ageing noticeably influence stacks' performance. This layer is composed of a FCS semi-empirical model and a Kalman filter. The utilized filter updates the FCS model parameters to compensate for the FCSs' performance drifts. The second layer (global management) is held accountable for splitting the power among components. This layer uses two inputs per each FCS, updated maximum power and efficiency, as well as the battery state of charge (SOC) and powertrain demanded power to perform the power sharing. The proposed EMS, called adaptive state machine strategy, employs the first two inputs to sort the FCSs out and the other inputs to do the power allocation. The ultimate results of the suggested strategy are compared with two commonly used power sharing methods, namely Daisy Chain and Equal Distribution. The results of the suggested EMS indicate promising improvement in the overall performance of the system. The performance validation is conducted on a developed test bench by means of hardware-in-the-loop (HIL) technique.
\end{abstract}

Index Terms - Kalman filter, Multi-Stack Fuel Cell Hybrid Electric Vehicle, Online energy management strategy, Semiempirical model

\section{INTRODUCTION}

$\mathrm{T}$ ransportation sector is widely blamed for the combustion of petroleum-derived commodities in internal combustion engines, which produce a fair amount of carbon dioxide [1]. Hence superseding the dirty energy sources by clear ones for

This work was supported in part by the Natural Sciences and Engineering Research Council of Canada (NSERC) and Canada Research Chairs program.

"Copyright (c) 2015 IEEE. Personal use of this material is permitted. However, permission to use this material for any other purposes must be obtained from the IEEE by sending a request to pubs-permissions@ieee.org."

A. Macias, M. Kandidayeni, and L. Boulon are with the Hydrogen Research Institute, Department of Electrical and Computer Engineering, Université du Québec à Trois-Rivières, QC G8Z 4M3, Canada (email: alvaro.omar.macias.fernandez@uqtr.ca, mohsen.kandi.dayeni@uqtr.ca, loic.boulon@uqtr.ca).

H. Chaoui is with the Intelligent Robotic and Energy Systems Research Group, Department of Electronics, Carleton University, Ottawa, ON K1S 5B6, Canada (e-mail: hicham.chaoui@carleton.ca). powering the vehicles is an important measure. Electric and hybrid electric vehicles can be appropriate substitutes for conventional vehicles. However, the latter still relies on fossil fuels and the former suffers from restricted driving range as well as long charging time. These pitfalls have paved the way for the emergence of fuel cell hybrid electric vehicles (FCHEVs) [2]. FCHEVs do not have the limitations of their competitors and benefit from definite merits, such as high efficiency, local pollution-free essence, and convenient maintenance, by comparison. Fuel cells (FCs) have not nevertheless achieved their utmost market development in the automotive industry yet due to some barriers such as confined hydrogen and its infrastructure availability, high price, and limited lifespan [3]. Multi-stack fuel cell system (MFCS), which is an arrangement of low power FC stacks (FCSs) rather than one high power stack, can be a remedy for some of the mentioned obstacles in the FCs development way [4]. MFCSs can be configured to provide modularity, which makes the FCS's replacement more convenient and fault tolerant to enable the system to keep operating in case of a malfunction. Above all, a proper architecture in MFCSs, i.e., one converter per FCS, provides more degrees of freedom and facilitates the employment of degraded mode and advanced energy management strategies (EMSs). On the other hand, the initial cost development of a MFCS is higher than a single stack system [5]. However, this drawback can be compensated by scale economy of modular configuration with small series production [6]. The utilization of another source of energy, such as battery, supercapacitor, etc., besides a FCS seems to be vital in vehicular applications due to the fact that FCSs have slow dynamics and are not capable of storing energy $[7,8]$. The extra source reduces degradation rate of the stack by absorbing the power peaks and is also used for energy recovery. Since a MFCS is composed of several sources with various features, the operating points of different components need to be efficiently ascertained by an EMS to elevate the overall performance of the system [9]. Most of EMSs deal with a single-stack FC system. However, these methods are applicable to a MFCS with slight modifications.

The existent EMSs in the literature fall into two categories of rule-based and optimization-based [10,11]. The rulebased group comprises deterministic and fuzzy rule-based, which can appear in the form of conventional [12], adaptive, 
and predictive approaches. The optimization-based group is composed of global and real-time methods in which a cost function is utilized to define fuel consumption and system efficiency [13-15]. In [16], an adaptive fuzzy based EMS is proposed for a FCHEV where the controller can embrace various driving conditions. However, according to the authors, the defined rule base needs to be updated when the FCS goes under degradation. In [17], new EMSs are proposed for a FCHEV, composed of a FCS, un ultracapacitor, and a battery, in a degraded operation modes based on the original strategy, which is a fuzzy rule-based EMS. In $[18,19]$, a multi-mode controller is proposed to split the power among the sources while a neural network based driving condition recognizer is used to select the right mode of operation. In [20], the combination of a low-pass filter and a fuzzy controller is used in a FCHEV to increase the lifetime of the FCS by limiting its current transitions and decrease the H2 consumption. In [21], a droop control-based EMS combined with a multimode and an equivalent consumption minimization strategy is used in a high-power FCHEV. In [22], a rule-based power-following and a wavelet-transformbased EMS are designed and their performance is compared in terms of lifetime of the FCS and the hydrogen consumption. In [23], an equivalent consumption minimization strategy based on sequential quadratic programming is proposed where the FCS is operated in the high-efficiency zone, battery acts as the main power source, and supercapacitor absorbs the power peak. In [24], a new formulation for dynamic programming in a FCHEV problem is suggested in which the work mode and FCS power are added as the state variables to solve the Markov problem. There are a few works in the literature to touch on the subject of EMS design for MFCSs. In [25], three power sharing algorithms, namely Equal Distribution, Daisy Chain, and optimal power splitting are compared. The comparison reveals that the optimal power splitting approach performs much better in high power region. In [26], the first two power sharing algorithms of the previous work are tested for a degraded mode operation scenario, where one of the FCSs stops working while the system is under operation. It has been shown that the designed MFCS can finish the task even if one of the FCSs fails. In [27], a multisource coordination strategy guarantees the SOC consensus of the storage systems in a MFCS.

The majority of the existing EMSs, regardless of their category or type, are premised upon FCS maps or unvarying mathematical models. In this light, these results remain valid only within a specific operating range. However, the energetic performance of a FCS alters by the operating conditions and degradation level variations through time [28, 29]. Some solutions based on extremum seeking strategies have been proposed to deal with the moving characteristics of a FCS. The first suggestion is to use the maximum power point tracking methods, such as perturb and observe or hill climbing, to track the real performance of a FCS. Such strategies have been used in $[30,31]$ for EMS purposes due to their convenient implementation. However, they are not very suitable for simultaneous identification of several characteristics, such as maximum power and efficiency points, in online applications since they require a separate search stage for each feature extraction. The second solution is the use of a parameter identification method coupled with an optimization algorithm. This solution offers two choices. The first one is to model the FCS multiphysics behavior. However, there is no reliable model representing ageing and degradation phenomena of a FCS system in the literature. The second choice is the use of an online parameter estimation method with a grey/black box model [32]. Although the black box-based strategies are easily applicable in real-time situations, they do not provide any insights into the physical phenomena inside the FCS and might become unreliable in case of confronting new situations. Moreover, the analysis of the results becomes more difficult with black box models due to the ambiguous input-output relationships. In this regard, the employment of semi-empirical models has recently come under attention in EMS design. These models contain meaningful physical parameters which enable a FC expert to analyze the results conveniently. In [33], a semiempirical FCS model, which is only based on current, is utilized and its parameters are identified by means of recursive filters to update the state of the FCS, and an optimization algorithm is then employed to find the operating points. The main idea in this line of work is to update the semi-empirical model parameters by means of a recursive algorithm and then use it in an EMS.

In this paper, a new two-layer adaptive EMS is proposed for a FCHEV with four parallel FCSs and a battery pack. Therefore, in the local layer, a semi-empirical FCS model coupled with Kalman filter (KF) is employed to keep track of the performance drifts. Immediately afterwards, in the global layer, the proposed power sharing algorithm distributes the power with the aim of diminishing the fuel consumption as well as increasing the durability. The contributions of this work lie in two important aspects. First, incorporating the online parameter estimation of FCSs into the design of an EMS for four FCSs and a battery pack. Second, the development of a hardware-in-the-loop (HIL) simulators for validating the proposed EMS in such multistack architecture, as opposed to other similar works in the literature which are mainly based on simulation. The generalized drivetrain architecture of the multi-stack FCHEV used in this research is shown in Fig. 1. This figure shows that the usage of the suggested EMS can be extended for $\mathrm{N}$ number of FCSs.

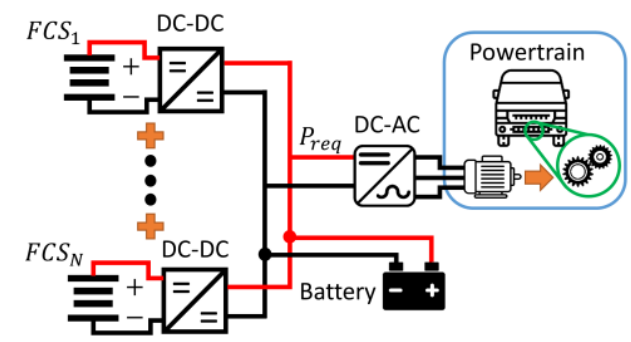

Fig. 1. Parallel configuration of a FCHEV with $\mathrm{N}$ number of FCSs

Section II outlines the FCS modelling along with the 
explanation of the first layer of the EMS. The proposed power sharing algorithm is detailed in section III. In Section IV, experimental outcomes are reported and explored. Finally, the conclusion is drawn in section VI.

\section{II.MODELLING}

In a FCHEV, the electric motor receives the power from both FCS and battery pack. The low speed vehicle of this work utilizes ACX-2043 motor, which is a 3-phase AC motor for propulsion. More specifications about the used vehicle in this work can be found in [34]. Four 500-W FCSs and a 335-Ah battery pack have been selected as the power sources. A DCDC converter is utilized to regulate the current flow of each PEMFC, while the battery pack is passively connected to the DC bus, similar to many other works in the literature $[15,19$, 22, 30, 35-41]. The difference between the demanded current from the motor inverter and the current flow of the FC system DC-DC converter is offset by the battery pack [35]. The battery has indeed a dual role of supplying the low-level requested power and absorbing the power peaks in this hybrid system. The characteristics of the utilized FCS and the battery are listed in Table I. From this table, it can be seen that the nominal voltage of the battery pack comes to $72 \mathrm{~V}$ and the open-circuit voltage of the FCS is $34 \mathrm{~V}$. Therefore, the battery pack voltage is always higher than the open-circuit voltage of the FCSs. The detailed information about the battery model is accessible in [42]. Herein, only the vehicle drivetrain and the FCS model development are discussed. The employed parallel configuration leads to more redundancy and modularity, which can enable fault-tolerant operation. The utilized hybrid system structure of this manuscript is presented in Fig. 2 in the form of HIL simulation. HIL is a beneficial step to develop a new EMS to test the control limitations and components restraints. Moreover, developing a complete multi-stack FCS test bench is expensive, and therefore HIL simulation can be used to validate the efficiency of any new EMS before implementation in the real system.

TABLE I

CHARACTERISTICS OF THE POWER SOURCES

\begin{tabular}{|c|c|}
\hline \multicolumn{2}{|c|}{ Fuel cell (Horizon H-500) } \\
\hline Rated power & $500 \mathrm{~W}$ \\
\hline No. cell & 36 cells \\
\hline Max current & $27 \mathrm{~A}$ \\
\hline Voltage range & $18 \mathrm{~V}-34 \mathrm{~V}$ \\
\hline \multicolumn{2}{|c|}{ Battery (US 8VGCHC XC2) } \\
\hline No. of packs in series & 9 \\
\hline Battery type & Lead-acid (deep cycle) \\
\hline Nominal voltage & $8 \mathrm{~V}$ \\
\hline Capacity C/100 & $335 \mathrm{Ah}$ \\
\hline
\end{tabular}

Two types of FCS model are used in the mentioned HIL: a multiphysics model (emulator) and a semi-empirical model. The real FCS and the emulators provide the necessary measured data for the local layer of the EMS while the semi-empirical model and identification method are used to determine the maximum operating points online. As it can be seen, this test bench comprises a Horizon H-500 air breathing proton exchange membrane FCS (real FCS) which is connected to a
National Instrument CompactRIO through its controller. An 8514 BK Precision DC Electronic Load is used to request load profiles from the open cathode FCS. According to the manufacturer, the difference between the pressure of the stack in the anode and cathode sides should be kept around $50.6 \mathrm{kPa}$. The pressure in the anode side is set to $55.7 \mathrm{kPa}$. The controller in this FCS has the following responsibilities:

- Controlling the stack temperature by acting on the blower.

- Opening the hydrogen valve.

- Controlling the purging interval of the purge valve.

The hydrogen consumption is directly dependent on the drawn current form the FCS and is determined by the proposed EMS. The utilized emulator in this work takes the temperature, current, and pressure as inputs and estimates the voltage of the stack as output. The stack temperature is calculated based on the energy conservation law where the forced convection equation includes the effect of the blower of the real FCS into the model. The hydrogen consumption is determined based on an empirical equation obtained by some performed experiments on the utilized FCS. The only thing that has been simplified is the effect of purging on the hydrogen consumption, which is a general assumption.

\section{A. Vehicle drivetrain model}

Similar to the majority of the EMS papers in the literature [43, 44], the vehicle modeling is done by taking only the efficiency of the DC/AC inverter as well as the motor into account as follows:

$P_{\text {req }}=P_{\text {trac }} / \eta_{\text {drive }}$

$\left\{\begin{array}{l}P_{\text {trac }}=\left(F_{a c c}+F_{r}+F_{a d}+F_{c r}\right) * v \\ \left\{\begin{array}{l}F_{r}=C_{r r} * m_{\text {total }} * g * \cos \alpha_{\text {slope }} \\ F_{a d}=0.5 * \rho_{\text {air }} * C_{x} * A_{\text {aero }} * v^{2} \\ F_{\text {acc }}=a_{\text {acc }} * m_{\text {total }}\end{array}\right.\end{array}\right.$

$\eta_{\text {drive }}=\eta_{\text {mech }} \cdot \eta_{D C / A C} \cdot \eta_{\text {motor }}$

Where $F_{a c c}$ is the acceleration force, $F_{r}$ is the friction of the tires, $F_{a d}$ is the aerodynamic drag resistance, $F_{c r}$ is the resistance of climbing, $C_{r r}$ is the coefficient of friction (0.015), $m_{\text {total }}$ is the total mass of the vehicle ( $\left.896 \mathrm{~kg}\right), g$ is the standard acceleration due to gravity $\left(9.81 \mathrm{~m} / \mathrm{s}^{2}\right), \alpha_{\text {slope }}$ is the slope of the road $\left(0^{\circ}\right), \rho_{\text {air }}$ is the air density $\left(1.2 \mathrm{~kg} / \mathrm{m}^{3}\right), C_{x}$ is the drag coefficient $(0.42), A_{\text {aero }}$ is the contact surface area $\left(4 \mathrm{~m}^{2}\right), v$ is the vehicle speed $(\mathrm{km} / \mathrm{h})$, and $a_{c c}$ is the vehicle acceleration. In this study, it is assumed that the vehicle is on a flat area and both of the friction and drag resistance are uniform and constant.

\section{B. Fuel cell stack emulator}

The utilized emulator involves formulating the electrochemical and thermal characteristics of a FCS. The electrochemical model is based on [32]. However, the charge double layer effect is added to it by using the proposed structure in [45]. The general equation for calculating the FCS output voltage $\left(V_{F C S}\right)$ is as follows: 


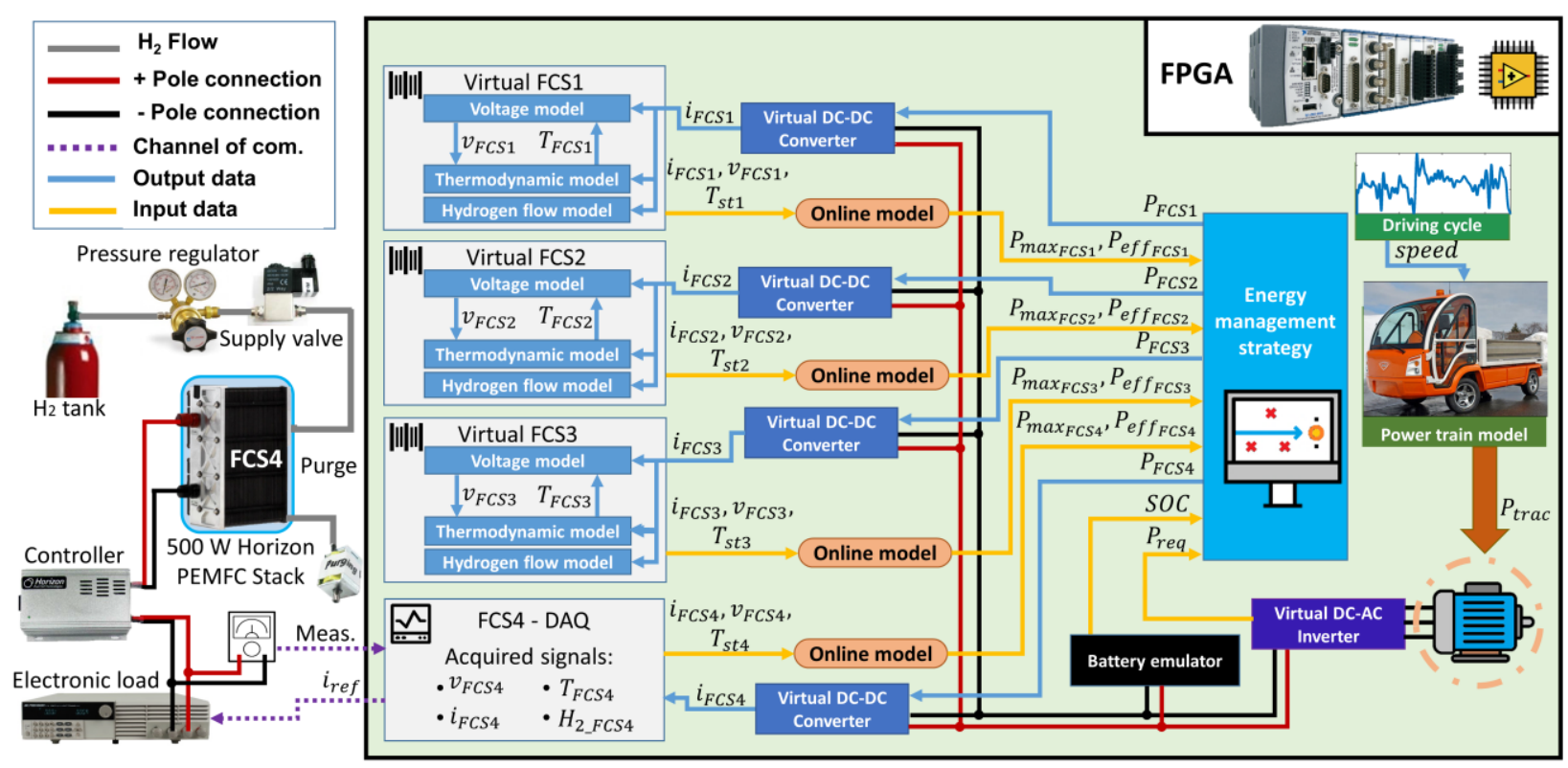

Fig. 2. The full-scale HIL

$V_{F C S}=N\left(E_{\text {Nernst }}+V_{\text {act }}+V_{\text {ohmic }}+V_{\text {con }}\right)$

where $N$ is the number of cells, $E_{\text {Nernst }}$ is the reversible cell potential $(\mathrm{V}), V_{\text {act }}$ is the activation loss $(\mathrm{V}), V_{\text {ohmic }}$ is the ohmic loss $(\mathrm{V})$, and $V_{c o n}$ is the concentration loss. The $E_{\text {Nernst }}$ is determined by:

$$
\begin{aligned}
& E_{\text {Nernst }}=1.229-0.85 \times 10^{-3}\left(T_{s t}-298.15\right)+4.3085 \times \\
& 10^{-5} T_{s t}\left[\ln \left(P_{H 2}\right)+0.5 \ln \left(P_{O 2}\right)\right]
\end{aligned}
$$

where $T_{s t}$ is the stack temperature $(\mathrm{K}), P_{H_{2}}$ is the hydrogen partial pressure in anode side $\left(\mathrm{Nm}^{-2}\right)$, and $P_{\mathrm{O} 2}$ is the oxygen partial pressure in cathode side $\left(\mathrm{Nm}^{-2}\right)$. The activation loss is caused by the slowness of the reactions happening on the electrode's surface and can be divided into two parts of temperature dependent activation loss $\left(V_{a c t 1}\right)$, and current and temperature dependant activation loss $\left(V_{\text {act2 }}\right)$ based on [46].

$$
\begin{aligned}
& V_{a c t}=-\left[\xi_{1}+\xi_{2} T_{s t}+\xi_{3} T_{s t} \ln \left(C_{2}\right)+\xi_{4} T_{s t} \ln \left(i_{F C S}\right)\right] \\
& V_{a c t 1}=-\left[\xi_{1}+\xi_{2} T_{s t}+\xi_{3} T_{s t} \ln \left(C O_{2}\right)\right] \\
& V_{a c t 2}=-\left[\xi_{4} T_{s t} \ln \left(i_{F C S}\right)\right] \\
& \qquad O_{2}=P_{O 2} / 5.08 \times 10^{6} \exp \left(-498 / T_{s t}\right)
\end{aligned}
$$

Where $\xi_{n}(n=1 \ldots 4)$ are empirical parameters, $\mathrm{CO}_{2}$ is the oxygen concentration $\left(\mathrm{mol} \mathrm{cm}^{-3}\right)$, and $i_{F C S}$ is the FCS current (A). The equivalent resistance of activation $\left(R_{a c t}\right)$ corresponding to $V_{a c t 2}$ is obtained by $V_{a c t 2} / i_{F C S}$. The Ohmic loss is defined as:

$V_{\text {ohmic }}=-i_{F C S} R_{\text {intern }}=-i_{F C S}\left(\zeta_{1}+\zeta_{2} T_{s t}+\zeta_{3} i_{F C S}\right)$

where $R_{\text {intern }}$ is the internal resistor $(\Omega)$, and $\zeta_{n}(n=1 \ldots 3)$ are empirical parameters. The concentration loss is defined by:

$V_{\text {con }}=B \ln \left(1-\frac{J}{J_{\max }}\right)$ where $B$ is an empirical coefficient, $J$ is the actual current density $\left(\mathrm{A} \mathrm{cm}^{-2}\right)$, and $J_{\text {max }}$ is the maximum current density (A $\left.\mathrm{cm}^{-2}\right)$. The equivalent resistor for the concentration loss $\left(R_{\text {con }}\right)$ is calculated by $V_{c o n} / i_{F C}$. Charge double layer phenomenon, which is formed along the porous cathode and the membrane, becomes important when sudden big changes happen in a short period of time. To incorporate this phenomenon in the FCS emulator modeling, the presented equivalent FCS model in Fig. 3 is used [46]. According to this circuit, the double layer charging effect can be defined as:

$V_{C}=\left(i_{F C S}-c d V_{C} / d t\right)\left(R_{a c t}+R_{c o n}\right)$

where $V_{C}$ is the double layer charging effect $(\mathrm{V})$, and $c$ is the capacitance (F), which can be in the order of several Farads due to the fact that the PEMFC electrodes are porous [45]. By taking the double layer effect into account, the output voltage of the FCS needs to be reformulated as:

$V_{F C S}=N\left(E_{\text {Nernst }}+V_{\text {act } 1}+V_{C}+V_{\text {ohmic }}\right)$

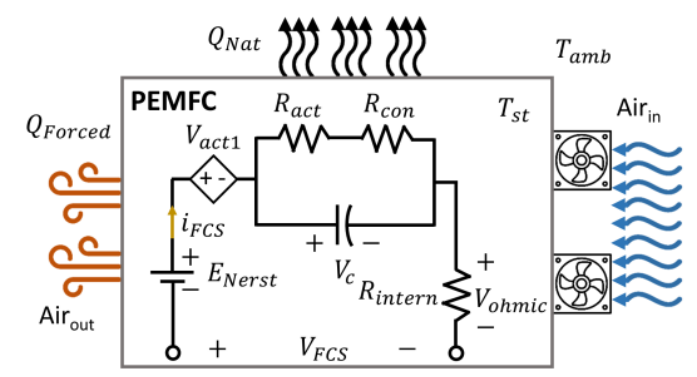

Fig. 3. The PEMFC system emulator

The thermal behavior of the open cathode FCS is modeled by employing the energy conservation law for a lumped system, explained in $[47,48]$. The energy balance for studying the 
thermal effect in the characteristics of the FCS can be formulated by:

$$
\begin{aligned}
& m_{s t} C_{s t} d T_{s t} / d t=\dot{Q}_{\text {reac }}-P_{s t}-Q_{N a t}-Q_{\text {Forced }} \\
& \dot{Q}_{\text {reac }}=V_{\text {max }} i N \\
& V_{\text {max }}=\Delta H / n F \\
& P_{s t}=V_{F C S} i_{F C S} \\
& Q_{N a t}=h_{N a t} A_{N a t}\left(T_{s t}-T_{c a}\right) \\
& Q_{\text {Forced }}=\alpha D_{\text {fan }} \rho_{\text {air }} A_{\text {Forced }} C_{p}\left(T_{s t}-T_{c a}\right)
\end{aligned}
$$

where, the temperature in the cathode $\left(T_{c a}\right)$ is assumed to be equal to the ambient temperature $\left(T_{a m b}\right), m_{s t}$ is stack mass (4.2 $\mathrm{kg}), C_{s t}$ is the specific heat capacity of stack (1260 J/kg K) [47], $T_{s t}$ is the stack temperature $(\mathrm{K}), \dot{Q}_{\text {reac }}$ is the released energy from electrochemical reaction $(\mathrm{J}), P_{s t}$ is the generated electrical power (W), $Q_{\text {Nat }}$ is the natural convection (J), $Q_{\text {Forced }}$ is the forced convection $(\mathrm{J}), \alpha$ is an empirical coefficient, $D_{\text {fan }}$ is the duty cycle of fan, $A_{\text {Forced }}$ is the cross-sectional area, and $C_{p}$ is the specific heat capacity of air. The hydrogen flow is estimated with a first order function based on experimental data. The model input variables are the current of the FCS $(A)$ and the duty cycle of the fan (\%).

$H_{2, \text { flow }}=a+b * i_{F C S}+c * D_{\text {fan }}$

As shown in Fig. 2, each FCS is connected to a virtual DC-DC converter. In this paper, a system level modeling by using an average model for the converter is used [49-51]. This model does not take the pulses and detailed switching of the MOSFET into account. The ON-OFF switching operations of the MOSFET are expressed by a new parameter, namely modulation ratio. Fig. 4a shows the electrical circuit of the utilized model and Fig. 4b presents this model by energetic macroscopic representation (EMR) to clarify the details [52, 53]. Assuming the time constant of the inductor is much greater than the switching period of the DC-DC converter, an average model [49-51, 54-56], as shown in Fig. 4, can be defined by:

$i_{F C S_{\text {meas }}}=\frac{1}{L_{\text {conv }}} \int\left(V_{F C S, \text { meas }}-V_{c h}-r_{L} i_{F C S_{\text {meas }}}\right) d t$

$V_{c h}=m_{F C S} V_{b a t}$

$i_{c h}=m_{F C S} i_{F C S_{\text {meas }}} \eta^{k}$ with $k=\left\{\begin{array}{c}1 \text { if } P_{\text {req }}>0 \\ -1 \text { if } P_{r e q}<0\end{array}\right.$

where $i_{F C S_{\text {meas }}}$ is the current through the inductor, $L_{\text {conv }}$ is the inductance value, $r_{L, c o n v}$ is the resistance of the smoothing inductor, $V_{c h}$ is the output voltage of the converter, $m_{F C S}$ is the DC-DC converter modulation ratio of the chopper, $V_{b a t}$ is the voltage in the DC bus, and $\eta$ is the converter efficiency (95\%). Assuming that the system operates in a continuous mode, the inductance is calculated in a way to avoid the flowing current through the inductor becomes zero. Other criteria, such as switching frequency and maximum ripple current, are defined heuristically to reach a trade-off between high switching frequency (high losses but low inductance) and low frequency (low losses but oversized inductor) [57]. The inductor parameters are: $L_{\text {conv }}=1.2 \mathrm{mH}$, and $r_{L, \text { conv }}=23.7 \mathrm{~m} \Omega$. As discussed in [58], the smoothing inductor model is a monoinput causal processor whose inversion is achieved by a PI closed-loop control of the output. $V_{c h \text {,ref }}$ is given by:

$$
\begin{aligned}
& V_{c h, r e f}=-K_{P I}(t)\left(i_{F C S_{r e f}}-i_{F C S_{\text {meas }}}\right)+V_{F C S, \text { meas }} \\
& m_{F C S}=\frac{V_{c h, r e f}}{V_{b a t}} \\
& i_{F C S_{\text {ref }}}=\frac{P_{F C S_{i}}}{V_{\text {bat }}}
\end{aligned}
$$

where $K_{P I}$ is a PI controller in the form of $K_{p}\left(1+K_{i} / s\right), i_{F C S_{\text {ref }}}$ is the reference current of the FCS calculated through dividing the reference power from the EMS by the voltage in the DC bus, and $i_{F C S_{\text {meas }}}$ is the actual current of the FCS. The control gains have been calculated by the PID Tuner of MATLAB $\left(K_{P}=\right.$ 0.001187 and $K_{I}=0.02375$ ).

a)

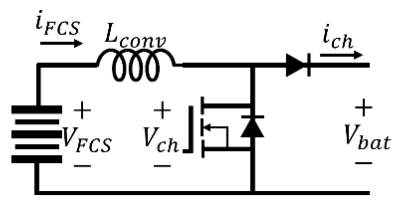

b)

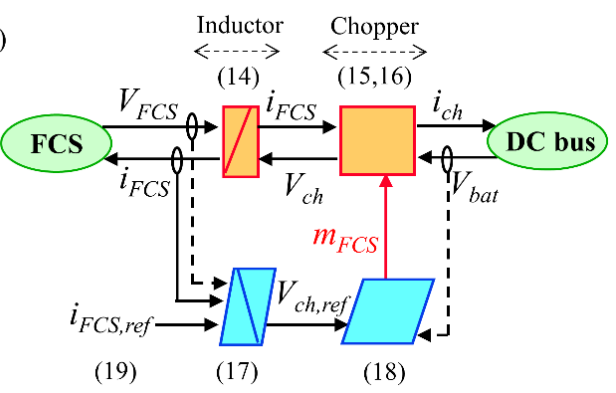

Fig. 4. a) Equivalent circuit model, and b) EMR of the DC-DC converter

Since the proposed EMS is meant to be adaptive, it is necessary to take into account the influence of ageing in the modeling part. In fact, FCS ageing phenomena is caused owing to several reasons and modeling such complicated phenomenon is an open topic in the literature. The main purpose of this paper is to show that the proposed EMS can embrace the effect of performance drifts owing to aging and operating condition variations. To clarify this functionality of the proposed EMS, the degradation path of the FCS output voltage needs to be simulated. To do so, several degradation models, namely exponential, pure logarithmic, log-linear, linear, and polynomial, are available in the literature [59-61]. However, there are two problems for using such models in this work. First, all of these models require experimental data corresponding to the degradation test of the system to fit the degradation model parameters. Second, a restriction on the stack voltage degradation model is that it does not allow untying the influence of the load variation, which causes current density variations, from that of the stack inner degradation, which affects almost all the three regimes of activation, ohmic, and concentration in a FCS characteristics curve. As the physical rules for interpreting the impacts of the degradation on the FCS model parameters are not known, in this paper, for simplicity of illustration and without loss of generality of the proposed approach, a polynomial function (20) is used to estimate how each of the parameters degrade over 
time and consequently estimate the degradation path of the FCS output voltage.

$x_{c}=a t^{2}+b t+x_{k}$

Where $t$ represents the time in terms of hours, $x_{k}$ is the initial value of each parameter of the FCS model in the beginning of life (BoL), $x_{c}$ is the actual value of each parameter, and $a$ and $b$ are fitting parameters. The fitting parameters of the degradation function ( $a$ and $b$ ) determine the degradation rate. These parameters are calculated based on the three FCS polarization curves shown in Fig. 5. These curves belong to three different states of health of a Horizon 500-W PEMFC. The FCS with the rated power of $500 \mathrm{~W}$ is in its BoL and considered as a new FCS. The one with almost $300 \mathrm{~W}$ is in its end of life (EoL) and assumed as an old FCS. Finally, the one with the rated power of $400 \mathrm{~W}$ is presumed in its middle of life $(\mathrm{MoL})$ and considered as a normal FCS. Using the presented polarization curves, the actual values of the voltage model parameters $\left(x_{c}\right)$ can be obtained for each of the BoL, MoL, and EoL states. It should be noted that the initial value of the voltage model parameters $\left(x_{k}\right)$ is equal to the actual value of the parameters in BoL since $t=0$, and consequently $a$ and $b$ will be zero. After obtaining $x_{c}$ and $x_{k}$, the two parameters of the defined degradation function should be calculated to predict the change of the voltage model initial parameters over time. In this work, the age of FCS at BoL is $0 \mathrm{~h}$ and at EoL is $5000 \mathrm{~h}$, according to the 2020 technical targets put forward by the U.S. Department of Energy in the Multi-Year Research, Development, and Demonstration Plan [62]. Since the age of the stack at BoL and EoL is known, the age of the FCS in MoL is obtained by a linear function with respect to the maximum power variation of the system $(\mathrm{MoL}=3500 \mathrm{~h})$. By knowing the age of each FCS in terms of hour $(t)$, the actual value of the parameters $\left(x_{c}\right)$, and the initial parameters $\left(x_{k}\right), a$ and $b$ can be calculated by fitting the equation to the data.

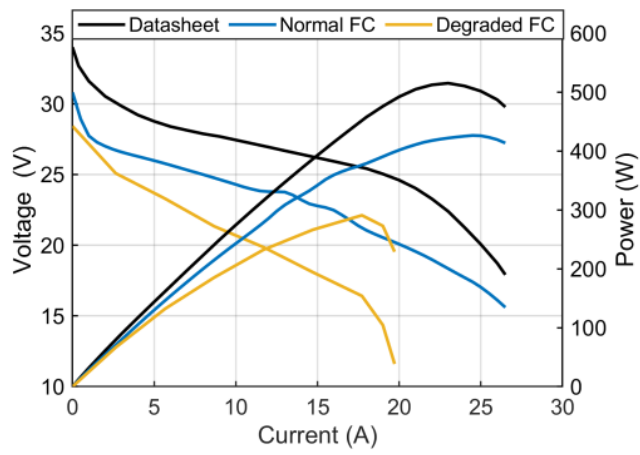

Fig. 5. The characteristic curves of the PEMFC stack for three different degradation levels (BoL, MoL, and EoL)

\section{Fuel cell stack emulator results}

In order to validate the performance of the designed emulator after calibration of the parameters with genetic algorithm (GA), the presented current profile in Fig. 6a is applied to the emulator and the output voltage and temperature of the emulator are compared to those of the real FCS. With respect to Fig. 6b, Fig. 6c, and Fig. 6d, the model is able to imitate the behavior of a 500 -W Horizon proton exchange membrane FCS satisfactorily. The obtained parameters of the model calibration process are listed in Table II.

a)
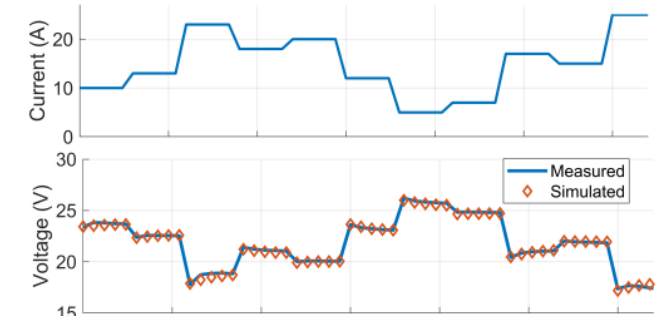

c)

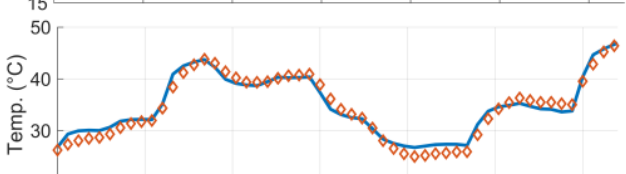

d)

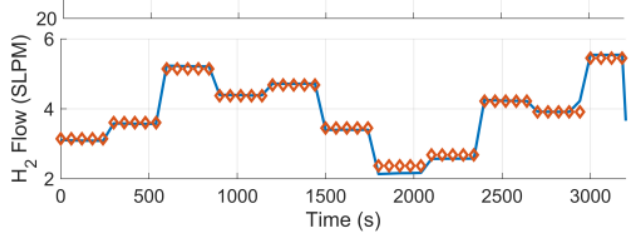

Fig. 6. Performance validation of the FCS emulator for fan duty cycle of $34 \%$, a) current profile, b) voltage estimation, c) temperature estimation, and d) hydrogen flow estimation

TABLE II

OBTAINED PARAMETERS FOR MODEL CALIBRATION

\begin{tabular}{ccc}
\hline \hline Param. & Value by GA & Reference \\
\hline$\xi_{1}$ & -1.505 & {$[32]$} \\
$\xi_{2}$ & $4.791 \times 10^{-3}$ & {$[32]$} \\
$\xi_{3}$ & $9.182 \times 10^{-5}$ & {$[32]$} \\
$\xi_{4}$ & $-1.892 \times 10^{-5}$ & {$[32]$} \\
$c$ & 5.201 & {$[45]$} \\
$B$ & 0.064 & {$[32]$} \\
$\zeta_{1}$ & $8.897 \times 10^{-3}$ & {$[32]$} \\
$\zeta_{2}$ & $1.941 \times 10^{-7}$ & {$[32]$} \\
$\zeta_{3}$ & $5.765 \times 10^{-6}$ & {$[32]$} \\
$\alpha$ & 0.0627 & {$[48]$} \\
\hline \hline
\end{tabular}

\section{ONLINE FUEL CELL STACK MODELLING}

A FCS experiences performance drifts during its lifetime. These drifts are because of degradation phenomenon, which happens slowly over time, and the influence of the operating conditions which are not included in the model. In order to take these effects into account, the model parameters need to be updated online to adapt the model to the real state of the FCS.

\section{A. Semi-empirical model}

Several semi-empirical models can be found in the literature for PEMFC stacks [63-65]. Among them, the model proposed by Amphlett et al. has been suggested for EMS purposes in a number of different works reviewed in [32]. This model is for a number of cells connected in series and assumes the same behavior for all the cells. The general formulation of this model can be given by (21) and (22), which have been already explained in section II.

$V_{F C S}=N\left(E_{\text {Nernst }}+V_{\text {act }}+V_{\text {ohmic }}+V_{\text {con }}\right)$ 
$\left\{\begin{array}{l}V_{\text {act }}=\xi_{1}+\xi_{2} T_{s t}+\xi_{3} T_{s t} \ln \left(C O_{2}\right)+\xi_{4} T_{s t} \ln \left(i_{F C S}\right) \\ V_{\text {ohmic }}=-i_{F C S} R_{\text {intern }}=-i_{F C S}\left(\zeta_{1}+\zeta_{2} T_{s t}+\zeta_{3} i_{F C S}\right) \\ V_{\text {con }}=B \ln \left(1-\frac{J}{J_{\max }}\right)\end{array}\right.$

\section{B. Online parameter identification}

In this work, online parameter identification is required since the parameters of a FCS model are time-varying. KF and recursive least square (RLS) are two well-known recursive filters, which have been successfully used in different engineering problems. In [32], the performance of KF and RLS have been compared for a FCS model parameter estimation problem and concluded that KF benefits from more robustness. In this regard, $\mathrm{KF}$ is used to identify the parameters of the introduced semi-empirical FCS model online. The structure of $\mathrm{KF}$ is as follows:

$$
\begin{aligned}
& \{x(t+1)=F(t+1 \mid t) x(t)+w(t) \\
& \{y(t)=H(t) x(t)+v(t) \\
& \hat{x}^{-}(t)=F(t \mid t-1) \hat{x}^{-}(t-1) \\
& P^{-}(t)=F(t \mid t-1) P(t-1) F^{T}(t \mid t-1)+Q(t-1) \\
& G(t)=P^{-}(t) H^{T}(t)\left[H(t) P^{-}(t) H^{T}(t)+R(t)\right]^{-1} \\
& \hat{x}(t)=\hat{x}^{-}(t)+G(t)\left(y(t)-H(t) \hat{x}^{-}(t)\right) \\
& P(t)=(I-G(t) H(t)) P^{-}(t)
\end{aligned}
$$

where $t$ is the discrete time, $x(t)$ is the state vector, $\hat{x}(t)$ is the estimate of the state vector, $\hat{x}^{-}(t)$ denotes priori estimate of the state vector, $F(t+1 \mid t)$ is the transition matrix, which takes the state vector from time $t$ to time $t+1, w(t)$ is the process noise, $y(t)$ is the output, $H(t)$ is the measurement matrix, $v(t)$ is the measurement noise, $P(t)$ is the error covariance matrix, $Q(t)$ is the process noise covariance matrix, $G(t)$ is the Kalman gain,

\begin{tabular}{|c|c|c|}
\hline Operators & SYMBOLS & Implementation description \\
\hline State vector & $x(t)$ & {$\left[\xi_{1}, \xi_{2}, \xi_{3}, \xi_{4}, \zeta_{1}, \zeta_{2}, \zeta_{3}, B\right]$} \\
\hline $\begin{array}{l}\text { Measurement } \\
\text { vector }\end{array}$ & $H(t)$ & $\begin{array}{l}{\left[1, T_{s t}, T_{s t} \ln \left(C O_{2}\right), T_{s t} \ln \left(i_{F C S}\right),-\right.} \\
\left.i_{F C S},-i_{F C S} T_{s t},-i_{F C S}{ }^{2}, \ln \left(1-\frac{J}{J_{\max }}\right)\right]\end{array}$ \\
\hline $\begin{array}{l}\text { Transition } \\
\text { matrix }\end{array}$ & $F(t+1 \mid t)$ & Identity matrix \\
\hline $\begin{array}{l}\text { Measured } \\
\text { output }\end{array}$ & $Y(t)$ & Measured $V_{F C S}$ from the real FCS \\
\hline
\end{tabular}
$R(t)$ is the measurement noise covariance matrix, and $I$ is the identity matrix. Table III shows the customization of the explained KF for the problem of FCS model parameter estimation.

TABLE III

KALMAN FILTER CUSTOMIZATION FOR THE IDENTIFICATION PROBLEM

Fig. 7 shows the process of integrating KF into the parameter estimation of the FCS on the developed HIL set-up. The measured data are used in the implemented model for testing the identification process. The information between CompactRIO and the PC is transferred by means of an Ethernet connection every 100 milliseconds. In this respect, it can be stated that KF receives the measured data every 100 milliseconds and updates the parameters of the model before the next measurement arrives. Then the updated model can be used for extracting useful information, such as maximum power and maximum efficiency, to be used in the EMS design.

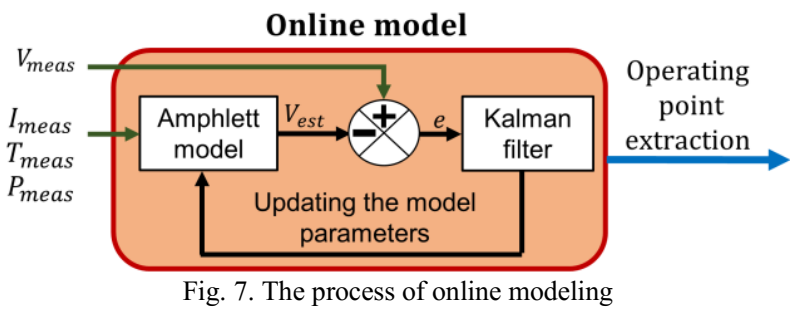

\section{C.FCS online model results analysis}

Fig. 8 presents the current profile and the corresponded measured voltage and temperature of the FCS. As is observed in Fig. 8c, the proposed online model can estimate the voltage with a satisfying precision. Fig. 9 compares the obtained power and efficiency curves of the online model with the curves of the real FCS. According to this figure, the maximum power and efficiency tracking has been successful. For each case of prediction, the mean square error (MSE) is reported in the caption of the figures to clarify the estimation quality.
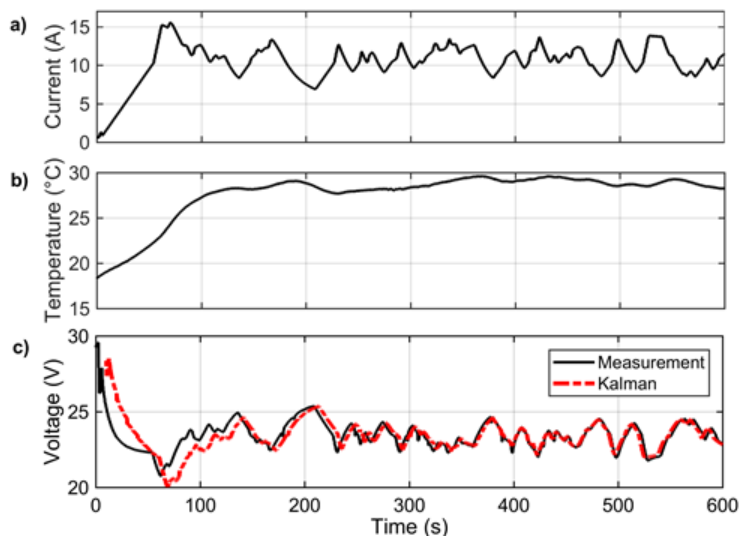

Fig. 8. The voltage estimation result. a) Applied current profile to the FCS, b) Measured temperature, c) Comparison of measured and estimated voltage (MSE: 0.1475)

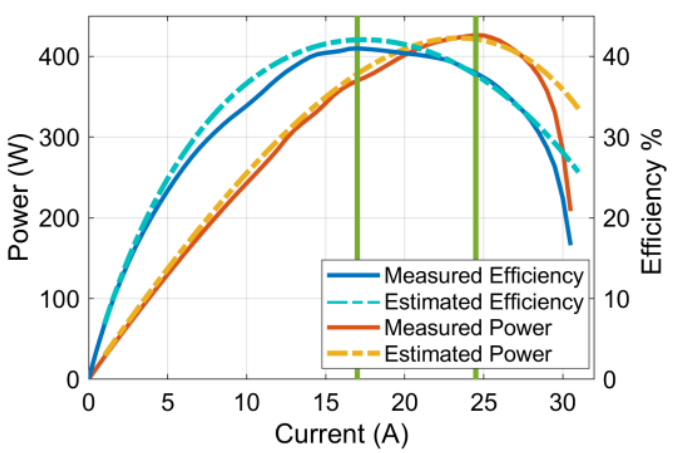

Fig. 9. Experimental and estimated power and efficiency curves by means of KF with a MSE of 3.44 (by using the extracted parameter at $200 \mathrm{~s}$ )

\section{ENERGY MANAGEMENT STRATEGY DESIGN}

In a multi-stack FCHEV, the EMS is responsible for distributing the requested power among the power sources with a view to reducing the system degradation as well as the hydrogen consumption. Declining the degradation rate of a FCHEV can be achieved by using the minimum possible number of FCSs (since the degradation rate is minimum when 
a FCS is off), proper management of the battery SOC, and operating the FCSs within their safe zone between maximum efficiency and maximum power points. By remaining in this area, FCS does not operate in activation and concentration zones which expedite the aging phenomenon. An adaptive state machine-based EMS is proposed in this section to fulfill the mentioned objectives, and its performance is compared with two common rule-based strategies explained hereinafter.

\section{A. Adaptive State Machine Based EMS}

The proposed online EMS has two fundamental operating layers, which are shown in Fig. 10. The first layer contains the described online model in the preceding section. In fact, it uses a semi-empirical FCS model and a KF to continuously update the maximum power and maximum efficiency of each FCS. According to the presented structure in Fig. 10, the previously explained FCS emulator acts as the real FCS and provides the necessary measurement signals, such as voltage, current, and temperature for the online model. FCS1 to FCS3 are emulators and FCS4 is a real 500-W Horizon proton exchange membrane FCS. The second layer distributes the power among the main powertrain components by using the minimum number of FCSs. As it can be seen in Fig. 10, this layer has six inputs, which are the updated maximum power and maximum efficiency points, the battery SOC, and the requested power.

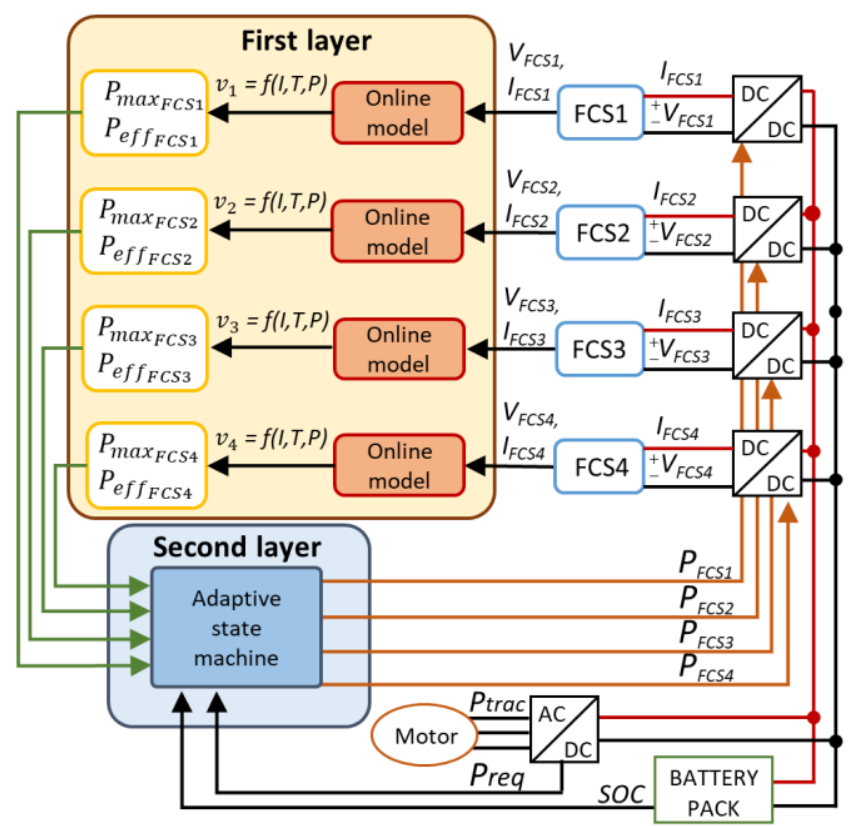

Fig. 10. EMS configuration of the discussed multi-stack FCHEV

The updated operating points are firstly used to reconfigure the order of using the FCSs. In fact, the FCSs are always put in a descending order from young to old. The age of each FCS is decided based on its actual maximum power, which means the more power, the younger. In this manuscript, the term "young FCS" refers to the stack with the highest power level and the term "old FCS" refers to the one with the lowest power level. The FCS with the highest power level has also the highest efficiency level. The second practical usage of these updated points is that the strategy employs them to operate the FCSs in their safe and efficient region. The other two inputs, which are battery SOC and demanded power, are used for power sharing. The battery SOC is estimated based on Coulomb Counting method, which is a well-known approach for SOC calculation in hybrid electric vehicles [66, 67], at each moment and sent to this layer as an input. The EMS decides on the operation of the FCSs based on the received input signals. Normally, two critical thresholds (minimum and maximum battery SOC) are defined for the batteries to avoid the occurrence of overcharge or over discharge. Different values for the minimum and maximum battery SOCs have been used in the literature [68]. In this work, a conservative target of $50 \%$ for the minimum battery SOC, which also offers an optimal balance of charge-discharge efficiency [69-71], is considered and the maximum SOC is set to $90 \%$. In this respect, while the requested power from the driver is less than the maximum efficiency points of each FCS, battery supplies the power. As the requested power goes over this point, FCSs are turned on one by one in order of young to old to meet the requested power. If the battery SOC decreases to the minimum threshold of $50 \%$, one of the FCSs works on the maximum power mode to recharge the battery. The proposed strategy first imposes a particular requested power to all the FCSs for a short while to perform the initial identification of their characteristics. Subsequently, it sorts them out in terms of their maximum power by utilizing an active table. Finally, it supplies the demanded power in a particular sequence in which the FCS with the best performance is first used up to its maximum power. If the demanded power exceeds the maximum power of the first stack, the second one in the active table is turned on only if this remnant is within its efficiency zone. Otherwise, the battery supplies this power and this principle is applied to the rest of the FCSs. It should be noted that the explained principle is applied by respecting some conditions. For instance, when the requested power decreases suddenly, all the active stacks will be operated in the maximum efficiency and even lower than maximum efficiency zone instead of turning off the active stacks. Applying this condition leads to the decrease of on/off cycles in the stacks as well as avoidance of operation in high power region. Another important point is that a dynamic limitation of $50 \mathrm{Ws}^{-1}$ has been considered for the operation of the FCSs to give the reactor some buffer time [33].

The proposed strategy degrades all the FCSs equally even if they have different aging rates. Fig. 11 presents the configuration of the proposed adaptive state machine EMS.

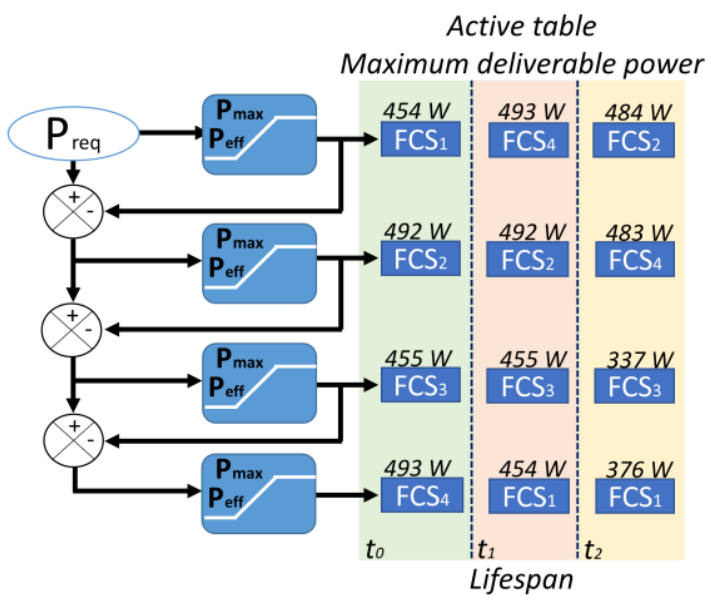


Fig. 11. Adaptive state machine EMS

\section{B. Equal Distribution strategy}

Equal Distribution strategy is based on dividing the requested power equally as the number of available FCSs. In this respect, it functions as a system with a big FCS rather than having several smaller modules. This strategy uses the requested power $\left(P_{\text {req }}\right)$ as the only input signal, as described below.

$$
P_{F C S_{i}}=P_{r e q} /_{N}
$$

Where $P_{F C i}$ is the requested power from the $F C S_{i}$, determined by (27), and $N$ is the number of available FCSs. In this strategy, all the FCSs have the same demanding power in spite of having different electrical capabilities in terms of supplying power and electrical response. The utilized FCSs in this strategy are aged at the same rate regardless of their initial degradation level.

\section{Daisy Chain strategy}

In a parallel configuration, Daisy Chain strategy utilizes the minimum number of FCSs to supply the requested power in a sequential order. This strategy employs only the first FCS until it reaches its maximum power. The next FCS is activated afterwards to supply the remaining requested power. Daisy Chain strategy considers the total demanded power from the system and the maximum power of each FCS as inputs. The main disadvantage of this strategy is that it uses the FCSs in a fixed order, causing the most part of degradation on the first stack. To avoid this problem, the FCSs are being sorted randomly each 30 minutes in this work.

\section{V.EXPERIMENT AND RESULTS ANALYSIS}

In order to investigate carefully the performance of the proposed EMS, three different scenarios are designed. In the first scenario, a ramp power profile is used to clearly show how the power sharing is performed by each of the strategies. The second scenario deals with the performance evaluation of the EMSs while using a real driving profile from Nemo vehicle. Finally, in the last scenario, a very long random step power profile is used to assess the degradation rate of the FCSs under different EMSs. The minimum requested power that Equal Distribution and Daisy Chain strategies impose to the system is limited to $80 \mathrm{~W}$ per FCS, which has been recommended as the minimum drawn power by the manufacturer, in order to avoid unnecessary turn on/off cycles as well as long open circuit voltage operation. It is worth noting that in scenarios 1 and 2, FCS4 is the real PEMFC stack, and FCS1 to FCS3 are the emulators. However, in scenario 3, which is a very long test and the usage of a real FCS is highly time-consuming, all the FCSs are emulators.

As there is no guarantee with regard to the strategies to finish in the same final SOC, a recharge step has been developed in this work to fully recharge the battery at the end of each test and the additional required hydrogen is added to the total hydrogen consumption. In scenario 1 , since the purpose of the test is only to depict the functionality of each strategy, the recharge step is only done by operating the stack at maximum power. However, in scenario 2 and 3, two approaches are adopted for performing the recharge step. Once, the battery pack is recharged by operating the FCS in the maximum efficiency point, and another time it is recharged by using the stack in the maximum power point and the results are reported separately to show the difference.

\section{1) Scenario 1:}

The principal purpose of designing this scenario is to clarify how the proposed strategy reconfigures the utilization order of the stacks based on their state of health. Moreover, it makes the functionality of different EMSs clear in terms of previously explained power distribution principle. In this respect, a rampup power profile, shown in Fig. 12a, is used for the purpose of this test. The initial ages for performing this test are presented in Table IV. These ages are used as the input of the degradation function to determine the characteristics of the system with respect to the aging phenomena.

TABLE IV

INITIAL CONDITIONS FOR THE RAMP PROFILE TEST

\begin{tabular}{cc}
\hline \hline FC system & Condition: Age $(\mathrm{h})$ \\
\hline FCS 1 & 1000 \\
FCS 2 & 4000 \\
FCS 3 & 1000 \\
FCS 4 & Real FC \\
\hline \hline
\end{tabular}

Fig. 12 shows the requested power from the system and the supplied power by the four FCSs and the battery for all the three strategies. From Fig. 12b, Equal Distribution strategy uses the battery in the beginning to supply the requested power up to 320 $\mathrm{W}$, which means $80 \mathrm{~W}$ per FCS. Then the FCSs equally supply the requested power from almost $150 \mathrm{~s}$ to around $700 \mathrm{~s}$. From $700 \mathrm{~s}$ onwards, since the level of the requested power is very high, FCS4 and FCS2, which are more degraded than the others, work in their maximum power and FCS1 and FCS3 converge to their maximum limit to meet the demanded power. The battery pack also helps the FCSs in this respect. With regard to the Daisy Chain strategy, Fig. 12c, it can be observed that this strategy turns on FCS4 when the requested power exceeds 80 $\mathrm{W}$ and uses this stack until its maximum power. Then, it turns on more FCSs as the requested power increases. One important aspect that should be pointed out here is that since this strategy is not aware of the current maximum deliverable power of the FCSs, it has used the more degraded FCSs more than other two FCSs, which can lead to less efficiency of the system. Furthermore, the supplied power by the battery in Fig. 12c indicates that when the degraded FCSs reach their maximum power, which is $400 \mathrm{~W}$ in this case, the strategy assumes that the rated power is $500 \mathrm{~W}$. As a result, battery supplies this difference between the actual maximum power of the FCS and its initial rated power. When the limiting power for activating the next FCS is passed, it will be turned on. Concerning the proposed adaptive state machine EMS, Fig. 12d, it can be seen that in the beginning, a specific power level is applied to all the FCSs to identify the real maximum power and efficiency points by means of the online modeling procedure. During this short period of time, the battery supplies the requested power. From $50 \mathrm{~s}$ onward, the battery meets the demanded power up to the point that the requested power reaches the maximum efficiency level of the FCS1. The strategy keeps using the FCS1 up to its identified maximum power level. Then the next FCSs are activated by respecting the same rules and regulations to satisfy 
the requested power. The point that needs to be highlighted is that in the proposed strategy, FCS1 and FCS3, which are in a better state of health according to the defined conditions in Table IV, are used more than the other two FCSs. This choice is made based on the performed identification process in the beginning and it can result in higher efficiency of the system, which will be explored more hereinafter.

Table $\mathrm{V}$ indicates the achieved hydrogen consumption by the discussed strategies. According to this table, the proposed EMS has the best fuel economy, which is the result of the reconfiguration of the order of the FCSs as well as keeping the FCSs operating conditions within the safe zone. In order to compare the achieved fuel consumption of the strategies, the initial SOC for all the strategies is $70 \%$ and at the end of each test the explained recharge step by using the maximum power of the stack is performed. The hydrogen consumption, needed to recharge the battery up to $100 \% \mathrm{SOC}$, is calculated and added to consumption of each strategy.

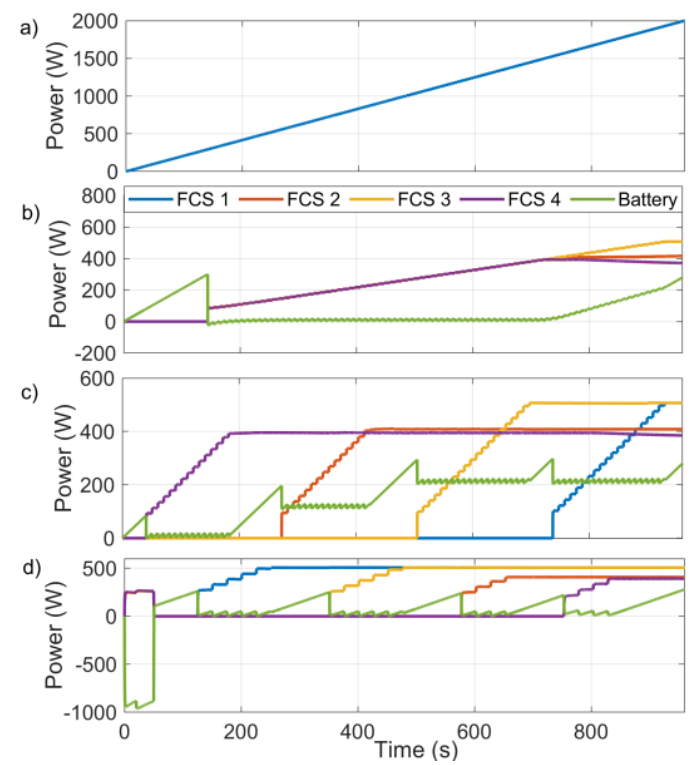

Fig. 12. Requested power profile (a), and power split results by: b) Equal Distribution, c) Daisy Chain, and d) Adaptive State Machine

TABLE V

HYDROGEN CONSUMPTION OF THE STRATEGIES IN SCENARIO 1

\begin{tabular}{cc}
\hline \hline Strategy & H2 consumption (gr) \\
\hline Equal Distribution & 45.12 \\
Daisy Chain & 46.28 \\
Adaptive State Machine & 44.02 \\
\hline \hline
\end{tabular}

\section{2) Scenario 2:}

In this scenario, Highway Fuel Economy Test Cycle (HWFET) is used to assess the power distribution in a real condition. This driving cycle and its corresponded requested power profile are shown in Fig. 13. It should be noted that for the purpose of this scenario, the presented driving cycle has been repeated six times and all the reported results have been achieved accordingly. Table VI shows the initial condition of the FCSs utilized in this test. According to this table, the initial maximum power of the FCS1 to FCS3 is $500 \mathrm{~W}$, and FCS4 is the real stack. The duration of the performed test in Scenario 2 is exactly 72 minutes and the quantity of degradation in this short interval is almost negligible. a)
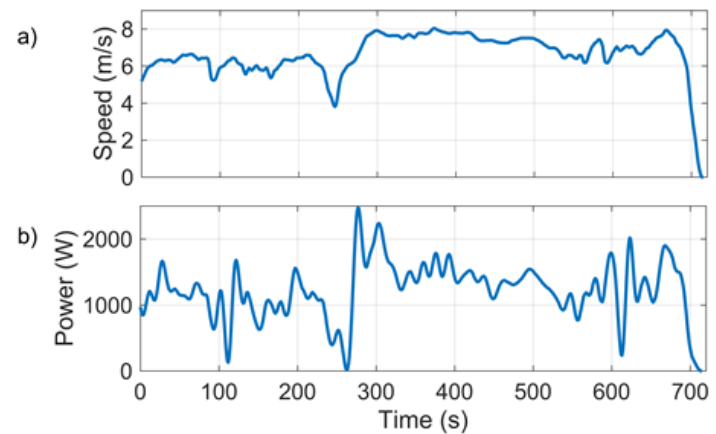

Fig. 13. HWFET profile, a) speed profile, b) requested power from Nemo drivetrain.

TABLE VI

INITIAL CONDITIONS IN SCENARIO 2

\begin{tabular}{cc}
\hline \hline FC system & Maximum power (W) \\
\hline FCS 1 & 500 \\
FCS 2 & 500 \\
FCS 3 & 500 \\
FCS 4 & 430 (real FCS) \\
\hline \hline
\end{tabular}

Fig. 14 represents the power distribution of requested power between the FCSs and the battery pack. The supplied power by the FCSs, shown in Fig. 14, is the sum of the power from each stack. To specify the drawn power from each stack, Fig. 15 presents the supplied power by the FCSs during the performed test. According to Fig. $15 \mathrm{c}$, the proposed adaptive state machine strategy decides on the order of using the FCSs almost during the first 3 minutes. Since all the FCS1 to FCS3 have the same initial conditions $(500 \mathrm{~W})$, it decides to use FCS1 first, FCS3 second, and FCS2 third and keeps the real stack (FCS4) off throughout this test. Moreover, the proposed strategy does not change the order of FCSs after that as no noticeable decay happens in the stacks during this Scenario. From 7 to 17 min, the strategy demands $400 \mathrm{~W}$ from FCS3 and afterwards it draws almost $500 \mathrm{~W}$ from each of FCS1 to FCS3 up to $20 \mathrm{~min}$. This

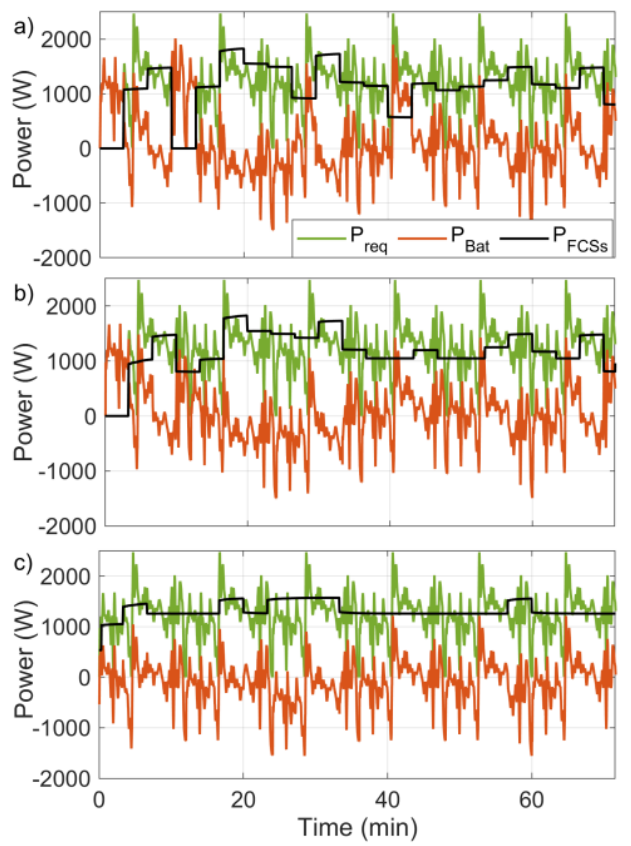


Fig. 14. Power distribution profiles, a) Equal Distribution, b) Daisy Chain, and c) Adaptive State Machine
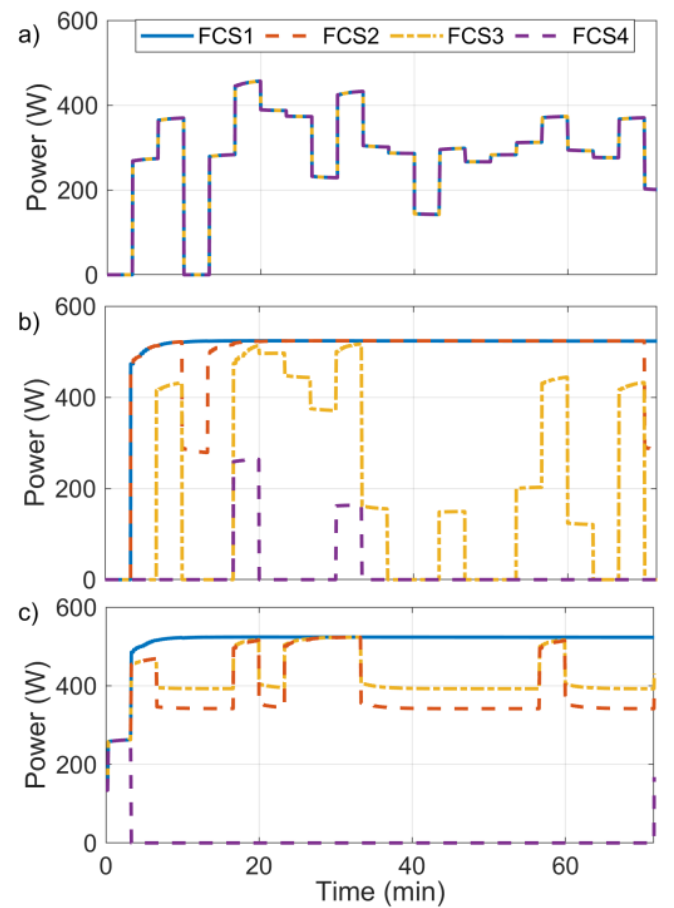

Fig. 15. The supplied power by each of the stacks, a) Equal Distribution, b) Daisy Chain, and c) Adaptive State Machine

increase in the drawn power from the stacks is due to the change of requested power from the system and the battery SOC. Fig. 16 shows the reference voltage of the utilized choppers (Fig. 16a) which is adjusted by the control signal obtained from the modulation ratios (Fig. 16b).
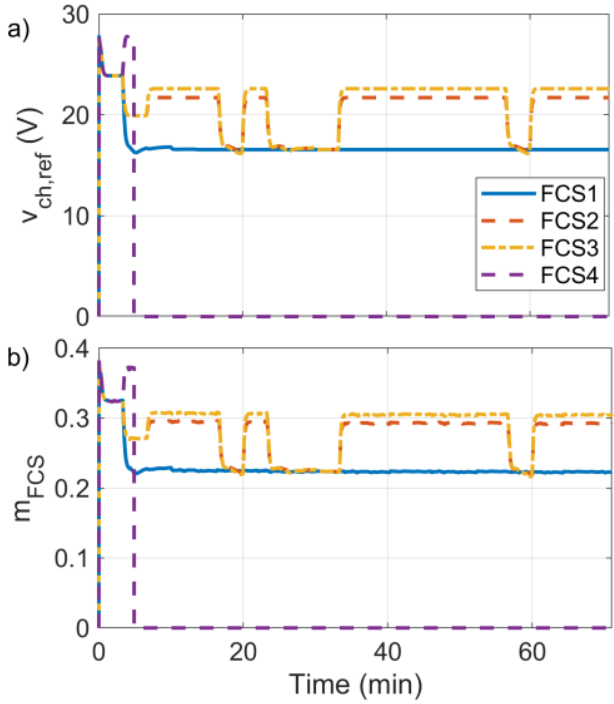

Fig. 16. a) The reference voltage for the chopper of the stacks; and b) corresponding modulation ratios

The variation of battery SOC is shown in Fig. 17 for all the strategies. Table VII compares the fuel consumption during the operation and added by the recharge step, number of on/off cycles, and the final SOC achieved by different strategies.
According to this table, the proposed strategy has improved the total fuel economy up to $14.7 \%$ and $7.3 \%$ compared to Equal

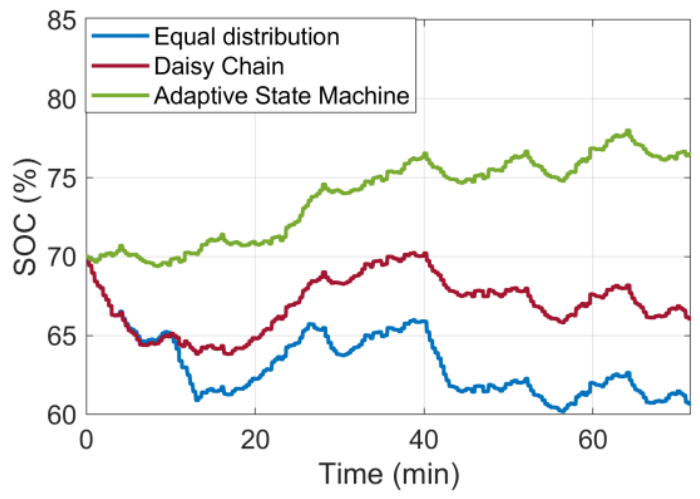

Fig. 17. SOC variation of the battery pack in scenario 2

Distribution and Daisy Chain strategies respectively. Moreover, the smaller number of on/off cycles, achieved by the proposed strategy, shows that the adaptive strategy has regard for the lifetime of the stacks and can noticeably increase it throughout time. To investigate the influence of initial and final battery SOC over the performance of the studied EMSs, scenario 2 has been repeated seven times starting with different initial SOCs $(55 \%, 60 \%, 65 \%, 70 \%, 75 \%, 80 \%$, and $85 \%)$. Subsequently, the difference between initial and final SOC $(\triangle S O C)$ achieved at the end of each test versus the hydrogen consumption is represented in Fig. 18. Form this figure, it is clear that for a given threshold of $\triangle S O C$, the proposed strategy consumes less hydrogen consumption compared to the other strategies. It should be noted that in case of Daisy Chain strategy, since the archived values for $\triangle S O C$ have substantial overlaps, they seem to be 4 tests. However, seven tests have been conducted and three of them are not clear due to the degree of overlap.

TABLE VII

PERFORMANCE COMPARISON OF THE STRATEGIES IN SCENARIO 2

\begin{tabular}{cccc}
\hline \hline Performance & $\begin{array}{c}\text { Equal } \\
\text { distribution }\end{array}$ & $\begin{array}{c}\text { Daisy } \\
\text { Chain }\end{array}$ & $\begin{array}{c}\text { Adaptive State } \\
\text { Machine }\end{array}$ \\
\hline $\mathrm{H}_{2}$ Consumption (gr) & 95.93 & 90.19 & 90.04 \\
Equivalent recharging H & \\
by Max. Power (gr) & 32.99 & 28.43 & 19.83 \\
$\begin{array}{c}\text { Equivalent recharging H } \\
\text { by Max. efficiency (gr) }\end{array}$ & 30.87 & 26.93 & 19.08 \\
$\begin{array}{c}\text { On/Off Cycle } \\
\text { Final SOC }\end{array}$ & 4 & 7 & 1 \\
\hline \hline
\end{tabular}

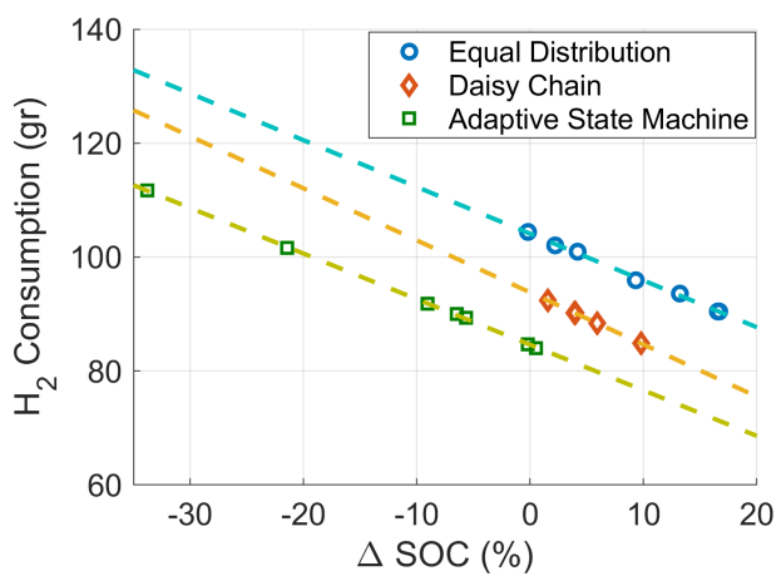


Fig. 18. The consumed hydrogen consumption versus the difference of initial and final battery $\mathrm{SOC}(\triangle S O C)$.

\section{3) Scenario 3:}

In this last scenario, a random step profile of 25 minutes, as shown in Fig. 19, is repeated for 300 hours. During this long test, different ageing rates are applied to the FCSs to evaluate the performance of the strategies regarding degradation management. As explained earlier, one of the main capabilities of the proposed EMS is to make the FC systems' degradation equal and the main purpose of designing this scenario is to illustrate this advantage. Throughout this scenario, the degradation rates of FCS1 to FCS4 are selected as 5.7, 3.7, 4.3, and 3.2 respectively. Each degradation rate acts as an accelerated factor, which is multiplied by the time variable $(t)$ of (20).

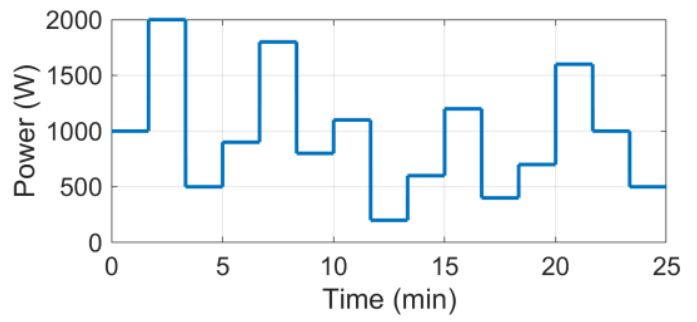

Fig. 19. Random step power profile
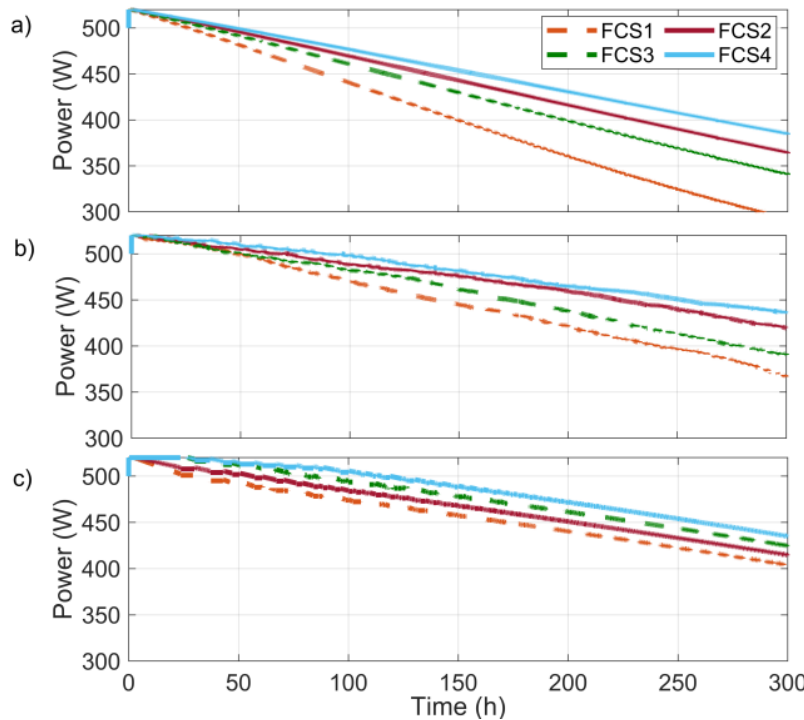

Fig. 20. Maximum power evolution during the 300 -h test. a) Equal Distribution, b) Daisy Chain, c) Adaptive State Machine

Fig. 20 demonstrates the maximum power evolution of each FCS which is affected by the specified degradation rates. This trend is a good measure to compare the performance of the EMSs through time. As is clear, the FCSs become degraded by different rates in case of Equal Distribution and Daisy Chain strategies. However, the proposed Adaptive State Machine EMS manages to keep the FCSs with almost the same degradation rate by reconfiguring their order from time to time. The maximum observable difference in the power of the FCSs is $10 \mathrm{~W}$. keeping the FCSs within a similar degradation rate can lower the hydrogen consumption, increase the system lifetime, and extend the replacement time of each stack. Considering a twenty-percent maximum power decline as an EoL indicator of each FCS, the final states of the FCSs in Fig. 20 show that only by using the proposed strategy all the FCSs will remain operative after this test. Fig. 21 clarifies the operation time of each FCS during the long test. As expected, the proposed EMS uses the more degraded FCSs less (FCS1:135.6 $\mathrm{h}$ and FCS3:148.1 h) than the other two FCSs (FCS2:189.2 $\mathrm{h}$ and FCS4:177.7 h). It is also observed that the Equal Distribution strategy utilizes all the FCSs for $280.7 \mathrm{~h}$, and Daisy Chain strategy does not respect the state of the health of the FCSs while using them (FCS1: 178.7 h, FCS2: 189.2 h, FCS3: 199.5 $\mathrm{h}$, and FCS4: 175.1). Table VIII presents the fuel consumption due to the operation and the recharge step, number of on/off cycles, and the final SOC attained by the strategies. This table shows that the proposed strategy has decreased the total hydrogen consumption up to $25.8 \%$ and $14.9 \%$ compared to other two methods.

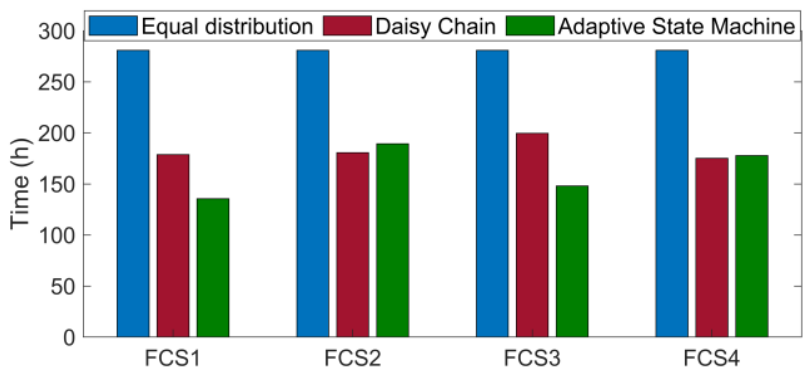

Fig. 21. Operation time of each FCS during the 300-h test

TABLE VIII

PERFORMANCE COMPARISON OF THE STRATEGIES IN SCENARIO 3

\begin{tabular}{cccc}
\hline \hline Performance & $\begin{array}{c}\text { Equal } \\
\text { distribution }\end{array}$ & $\begin{array}{c}\text { Daisy } \\
\text { Chain }\end{array}$ & $\begin{array}{c}\text { Adaptive State } \\
\text { Machine }\end{array}$ \\
\hline $\mathrm{H}_{2}$ Consumption (kg) & 11.5 & 10.04 & 8.54 \\
Equivalent recharging H & \\
by Max. power (gr) & 39.12 & 20.49 & 19.37 \\
$\begin{array}{c}\text { Equivalent recharging H} H_{2} \\
\text { by Max. efficiency (gr) }\end{array}$ & 37.05 & 19.71 & 18.83 \\
$\quad \begin{array}{c}\text { On/Off Cycle } \\
\text { Final SOC }\end{array}$ & 860 & 3506 & 425 \\
\hline \hline
\end{tabular}

\section{CONCLUSION}

This paper presents the design of an adaptive EMS for a multistack FCHEV. The proposed strategy utilizes the battery SOC, requested power, and maximum power and efficiency points of the FCSs to conduct the power split among four FCSs and a battery pack. The maximum power and efficiency points of the FCSs are continuously determined by using an online model composed of a KF integrated into a FCS semi-empirical model. The updated operating points are used by the strategy to decide on two essential things: first, ordering the stacks from young to old based on which they will be being used by the EMS. Second, determining the safe operating zone of each FCS, which is between maximum efficiency and maximum power points, to enhance their lifetime. The proposed strategy first updates the order of stacks based on the information provided by the online modeling layer. Subsequently, it uses the minimum possible number of stacks to meet the requested power by switching on the FCSs one by one and operating them in their efficient zones. To justify the functionality of the proposed EMS, three scenarios with different purposes have 
been designed and implemented in the developed HIL set-up. The first scenario mainly indicates the order reconfiguration capability of the proposed strategy to use the stacks more efficiently. The second scenario deals with the performance assessment while confronting a real driving condition. Finally, the third scenario is a long simulation test (a 300-h driving profile) to emphasize the importance of lifetime consideration in the EMS design. The analyses of the obtained results from different scenarios highlight the superior performance of the proposed EMS in terms of ameliorating the fuel economy and lifetime. In fact, compared to the obtained hydrogen consumption by Equal Distribution and Daisy Chain strategies, $2.4 \%$ and $4.8 \%$ of reduction in scenario $1,14.7 \%$ and $7.3 \%$ of decline in scenario 2 , and $25.8 \%$ and $14.9 \%$ of decrease in scenario 3 are observed respectively. The outcomes of this manuscript suggest the following directions for future researches:

- Including a more complicated ageing model and performing an ageing study while using the proposed EMS.

- Developing an EMS based on optimal control theory for the proposed multi-stack FCHEV structure and comparing the results with this work.

- This paper proposes an EMS for the existing energy systems in which the battery is connected directly to the DC bus and FCS connected through a DC/DC converter. In this regard, sizing of the battery pack is a very important step, which is not addressed in this paper, to ensure the maximum current levels imposed by the powertrain and DC/AC converter stay under the charge/discharge current limitations. However, owing to system cost and weight/footprint constraints, oversizing the battery pack to fulfill the worst-case scenario may not be an attractive option. In future, several solutions, such as limiting the acceleration (control of the DC/AC converter of the powertrain) or using an additional DC/DC converter for the battery, can be investigated to propose the most beneficial approach in a FCHEV.

\section{REFERENCES}

module fuel cell hybrid power system," in 2017 29th Chinese Control And Decision Conference (CCDC), 2017, pp. 4944-4948.
J. Snoussi, S. B. Elghali, M. Benbouzid, and M. F. Mimouni, "Optimal Sizing of Energy Storage Systems Using FrequencySeparation-Based Energy Management for Fuel Cell Hybrid Electric Vehicles," IEEE Transactions on Vehicular Technology,

vol. 67, pp. 9337-9346, 2018.
M. Pourabdollah, B. Egardt, N. Murgovski, and A. Grauers, "Convex Optimization Methods for Powertrain Sizing of Electrified Vehicles by Using Different Levels of Modeling Details," IEEE Transactions on Vehicular Technology, vol. 67, pp. 1881-1893, 2018.

Y. Huang, H. Wang, A. Khajepour, B. Li, J. Ji, K. Zhao, et al., "A review of power management strategies and component sizing methods for hybrid vehicles," Renewable and Sustainable Energy Reviews, vol. 96, pp. 132-144, 2018/11/01/2018.

M. Yue, S. Jemei, R. Gouriveau, and N. Zerhouni, "Review on health-conscious energy management strategies for fuel cell hybrid electric vehicles: Degradation models and strategies," International Journal of Hydrogen Energy, 2019/02/18/ 2019.

H. S. Das, C. W. Tan, and A. H. M. Yatim, "Fuel cell hybrid electric vehicles: A review on power conditioning units and topologies," Renewable and Sustainable Energy Reviews, vol. 76, pp. 268-291, 2017.

S. Ahmadi, S. M. T. Bathaee, and A. H. Hosseinpour, "Improving fuel economy and performance of a fuel-cell hybrid electric vehicle (fuel-cell, battery, and ultra-capacitor) using optimized energy management strategy," Energy Conversion and Management, vol. 160, pp. 74-84, 2018/03/15/2018.

N. Sulaiman, M. A. Hannan, A. Mohamed, P. J. Ker, E. H. Majlan, and W. R. Wan Daud, "Optimization of energy management system for fuel-cell hybrid electric vehicles: Issues and recommendations," Applied Energy, vol. 228, pp. 2061-2079, 2018/10/15/ 2018.

S. Mane, M. Mejari, F. Kazi, and N. Singh, "Improving Lifetime of Fuel Cell in Hybrid Energy Management System by LureLyapunov-Based Control Formulation," IEEE Transactions on Industrial Electronics, vol. 64, pp. 6671-6679, 2017.

R. Álvarez Fernández, S. Corbera Caraballo, F. Beltrán Cilleruelo, and J. A. Lozano, "Fuel optimization strategy for hydrogen fuel cell range extender vehicles applying genetic algorithms," Renewable and Sustainable Energy Reviews, vol. 81, pp. 655-668, 2018/01/01/ 2018.

J. Chen, C. Xu, C. Wu, and W. Xu, "Adaptive Fuzzy Logic Control of Fuel-Cell-Battery Hybrid Systems for Electric Vehicles," IEEE Transactions on Industrial Informatics, vol. 14, pp. 292-300, 2018. J. Solano, D. Hissel, and M. Pera, "Fail-Safe Power for Hybrid Electric Vehicles: Implementing a Self-Sustained Global Energy Management System," IEEE Vehicular Technology Magazine, vol. 13, pp. 34-39, 2018.

R. Zhang, J. Tao, and H. Zhou, "Fuzzy Optimal Energy Management for Fuel Cell and Supercapacitor Systems Using Neural Network Based Driving Pattern Recognition," IEEE Transactions on Fuzzy Systems, vol. 27, pp. 45-57, 2019.

[19] K. Song, F. Li, X. Hu, L. He, W. Niu, S. Lu, et al., "Multi-mode energy management strategy for fuel cell electric vehicles based on driving pattern identification using learning vector quantization neural network algorithm," Journal of Power Sources, vol. 389, pp. 230-239, 2018/06/15/2018.

[20] R. Zhang and J. Tao, "GA-Based Fuzzy Energy Management System for FC/SC-Powered HEV Considering H2 Consumption and Load Variation," IEEE Transactions on Fuzzy Systems, vol. 26, pp. 1833-1843, 2018.

[21] Q. Li, T. Wang, C. Dai, W. Chen, and L. Ma, "Power Management Strategy Based on Adaptive Droop Control for a Fuel Cell-BatterySupercapacitor Hybrid Tramway," IEEE Transactions on Vehicular Technology, vol. 67, pp. 5658-5670, 2018.

[22] K. Song, H. Chen, P. Wen, T. Zhang, B. Zhang, and T. Zhang, "A comprehensive evaluation framework to evaluate energy management strategies of fuel cell electric vehicles," Electrochimica Acta, vol. 292, pp. 960-973, 2018/12/01/ 2018.

[23] H. Li, A. Ravey, A. N'Diaye, and A. Djerdir, "A novel equivalent consumption minimization strategy for hybrid electric vehicle powered by fuel cell, battery and supercapacitor," Journal of Power Sources, vol. 395, pp. 262-270, 2018. 
[24] W. Zhou, L. Yang, Y. Cai, and T. Ying, "Dynamic programming for new energy vehicles based on their work modes Part II: Fuel cell electric vehicles," Journal of Power Sources, vol. 407, pp. 92-104, 2018/12/15/2018.

[25] J. E. Garcia, D. F. Herrera, L. Boulon, P. Sicard, and A. Hernandez, "Power sharing for efficiency optimisation into a multi fuel cell system," in 2014 IEEE 23rd International Symposium on Industrial Electronics (ISIE), 2014, pp. 218-223.

[26] N. Marx, D. C. T. Cárdenas, L. Boulon, F. Gustin, and D. Hissel, "Degraded mode operation of multi-stack fuel cell systems," IET Electrical Systems in Transportation, vol. 6, pp. 3-11, 2016.

[27] Y. Han, Q. Li, T. Wang, W. Chen, and L. Ma, "Multisource Coordination Energy Management Strategy Based on SOC Consensus for a PEMFC-Battery-Supercapacitor Hybrid Tramway," IEEE Transactions on Vehicular Technology, vol. 67, pp. 296-305, 2018.

[28] F. J. Vivas, A. d. 1. Heras, F. Segura, and J. M. Andújar, "Cell voltage monitoring All-in-One. A new low cost solution to perform degradation analysis on air-cooled polymer electrolyte fuel cells," International Journal of Hydrogen Energy, 2019/01/24/ 2019.

[29] T. Zhang, P. Wang, H. Chen, and P. Pei, "A review of automotive proton exchange membrane fuel cell degradation under start-stop operating condition," Applied Energy, vol. 223, pp. 249-262, 2018/08/01/ 2018 .

[30] D. Zhou, A. Al-Durra, I. Matraji, A. Ravey, and F. Gao, "Online Energy Management Strategy of Fuel Cell Hybrid Electric Vehicles: A Fractional-Order Extremum Seeking Method," IEEE Transactions on Industrial Electronics, vol. 65, pp. 6787-6799, 2018.

[31] N. Bizon and P. Thounthong, "Real-time strategies to optimize the fueling of the fuel cell hybrid power source: A review of issues, challenges and a new approach," Renewable and Sustainable Energy Reviews, vol. 91, pp. 1089-1102, 2018/08/01/ 2018.

[32] M. Kandidayeni, A. Macias, A. A. Amamou, L. Boulon, S. Kelouwani, and H. Chaoui, "Overview and benchmark analysis of fuel cell parameters estimation for energy management purposes," Journal of Power Sources, vol. 380, pp. 92-104, 2018.

[33] K. Ettihir, L. Boulon, and K. Agbossou, "Optimization-based energy management strategy for a fuel cell/battery hybrid power system," Applied Energy, vol. 163, pp. 142-153, 2016.

[34] F. Martel, S. Kelouwani, Y. Dubé, and K. Agbossou, "Optimal economy-based battery degradation management dynamics for fuelcell plug-in hybrid electric vehicles," Journal of Power Sources, vol. 274, pp. 367-381, 2015/01/15/2015.

[35] X. Wu, X. Hu, X. Yin, L. Li, Z. Zeng, and V. Pickert, "Convex programming energy management and components sizing of a plugin fuel cell urban logistics vehicle," Journal of Power Sources, vol. 423, pp. 358-366, 2019/05/31/2019.

[36] Y. Wang, S. J. Moura, S. G. Advani, and A. K. Prasad, "Power management system for a fuel cell/battery hybrid vehicle incorporating fuel cell and battery degradation," International Journal of Hydrogen Energy, 2019/02/28/ 2019.

[37] H. Li, A. Ravey, A. N'Diaye, and A. Djerdir, "Online adaptive equivalent consumption minimization strategy for fuel cell hybrid electric vehicle considering power sources degradation," Energy Conversion and Management, vol. 192, pp. 133-149, 2019/07/15/ 2019.

[38] H. Jiang, L. Xu, J. Li, Z. Hu, and M. Ouyang, "Energy management and component sizing for a fuel cell/battery/supercapacitor hybrid powertrain based on two-dimensional optimization algorithms," Energy, vol. 177, pp. 386-396, 2019/06/15/ 2019.

[39] X. Hu, C. Zou, X. Tang, T. Liu, and L. Hu, "Cost-optimal energy management of hybrid electric vehicles using fuel cell/battery health-aware predictive control," IEEE Transactions on Power Electronics, pp. 1-1, 2019.

[40] M. Carignano, V. Roda, R. Costa-Castelló, L. Valiño, A. Lozano, and F. Barreras, "Assessment of Energy Management in a Fuel Cell/Battery Hybrid Vehicle," IEEE Access, vol. 7, pp. 1611016122, 2019.

[41] D. Shen, C. Lim, P. Shi, and P. Bujlo, "Energy Management of Fuel Cell Hybrid Vehicle Based on Partially Observable Markov Decision Process," IEEE Transactions on Control Systems Technology, pp. 1-13, 2018.

[42] K. Thirugnanam, P. E. R. J. T, M. Singh, and P. Kumar, "Mathematical Modeling of Li-Ion Battery Using Genetic
Algorithm Approach for V2G Applications," IEEE Transactions on Energy Conversion, vol. 29, pp. 332-343, 2014.

[43] J. P. F. Trovão, M. Roux, M. É, and M. R. Dubois, "Energy- and Power-Split Management of Dual Energy Storage System for a Three-Wheel Electric Vehicle," IEEE Transactions on Vehicular Technology, vol. 66, pp. 5540-5550, 2017.

[44] F. Martel, Y. Dubé, S. Kelouwani, J. Jaguemont, and K. Agbossou, "Long-term assessment of economic plug-in hybrid electric vehicle battery lifetime degradation management through near optimal fuel cell load sharing," Journal of Power Sources, vol. 318, pp. 270-282, 2016/06/30/ 2016.

[45] C. Wang, M. H. Nehrir, and S. R. Shaw, "Dynamic Models and Model Validation for PEM Fuel Cells Using Electrical Circuits," IEEE Transactions on Energy Conversion, vol. 20, pp. 442-451, 2005.

[46] C. Restrepo, T. Konjedic, A. Garces, J. Calvente, and R. Giral, "Identification of a Proton-Exchange Membrane Fuel Cell's Model Parameters by Means of an Evolution Strategy," IEEE Transactions on Industrial Informatics, vol. 11, pp. 548-559, 2015.

[47] Y. X. Wang, F. F. Qin, K. Ou, and Y. B. Kim, "Temperature Control for a Polymer Electrolyte Membrane Fuel Cell by Using Fuzzy Rule," IEEE Transactions on Energy Conversion, vol. 31, pp. 667$675,2016$.

[48] K. Ou, W.-W. Yuan, M. Choi, S. Yang, and Y.-B. Kim, "Performance increase for an open-cathode PEM fuel cell with humidity and temperature control," International Journal of Hydrogen Energy, vol. 42, pp. 29852-29862, 2017.

[49] A. Castaings, W. Lhomme, R. Trigui, and A. Bouscayrol, "Comparison of energy management strategies of a battery/supercapacitors system for electric vehicle under real-time constraints," Applied Energy, vol. 163, pp. 190-200, 2016.

[50] B. Nguyen, R. German, J. P. F. Trovão, and A. Bouscayrol, "RealTime Energy Management of Battery/Supercapacitor Electric Vehicles Based on an Adaptation of Pontryagin's Minimum Principle," IEEE Transactions on Vehicular Technology, vol. 68, pp. 203-212, 2019.

[51] A. Allegre, A. Bouscayrol, and R. Trigui, "Flexible real-time control of a hybrid energy storage system for electric vehicles," IET Electrical Systems in Transportation, vol. 3, pp. 79-85, 2013.

[52] A. Bouscayrol, B. Davat, B. de Fornel, B. François, J. P. Hautier, F. Meibody-Tabar, et al., "Control structures for multi-machine multiconverter systems with upstream coupling," Mathematics and Computers in Simulation, vol. 63, pp. 261-270, 2003/11/17/ 2003.

[53] A. Bouscayrol, J.-P. Hautier, and B. Lemaire-Semail, "Graphic Formalisms for the Control of Multi-Physical Energetic Systems: COG and EMR," in Systemic Design Methodologies for Electrical Energy Systems, I. a. Wiley, Ed., ed, 2012.

[54] B. S. Sami, N. Sihem, B. Zafar, and C. Adnane, "Performance study and efficiency improvement of Hybrid Electric System dedicated to transport application," International Journal of Hydrogen Energy, vol. 42, pp. 12777-12789, 2017.

[55] L. Xu, P. Hong, C. Fang, J. Li, M. Ouyang, and W. Lehnert, "Interactions between a polymer electrolyte membrane fuel cell and boost converter utilizing a multiscale model," Journal of Power Sources, vol. 395, pp. 237-250, 2018/08/15/2018.

[56] P. Hong, J. Li, L. Xu, M. Ouyang, and C. Fang, "Modeling and simulation of parallel DC/DC converters for online AC impedance estimation of PEM fuel cell stack," International Journal of Hydrogen Energy, vol. 41, pp. 3004-3014, 2016/01/30/ 2016.

[57] R. R. Meghana, S. B.N, and H. R. Mohan, "Single Phase Active PFC Using Boost Converter," International Journal of Advance Computational Engineering and Networking, vol. 1, 2014.

[58] D. Hernández-Torres, D. Riu, O. Sename, and F. Druart, "Robust optimal control strategies for a hybrid fuel cell power management system," in IECON 2010 - 36th Annual Conference on IEEE Industrial Electronics Society, 2010, pp. 698-703.

[59] D. Zhang, "Contribution to prognostics of PEM fuel cells: approaches based on degradation information at multiple levels," Communauté Université Grenoble Alpes, 2018.

[60] J. K. Kimotho, T. Meyer, and W. Sextro, "PEM fuel cell prognostics using particle filter with model parameter adaptation," in 2014 International Conference on Prognostics and Health Management, 2014, pp. 1-6. 
[61] H. Liu, J. Chen, D. Hissel, and H. Su, "Remaining useful life estimation for proton exchange membrane fuel cells using a hybrid method," Applied Energy, vol. 237, pp. 910-919, 2019/03/01/ 2019.

[62] U. S. D. o. Energy. (2017, May). Fuel Cell Technologies Office Multi-Year Research, Development, and Demonstration Plan [Online].

https://www.energy.gov/eere/fuelcells/downloads/fuel-celltechnologies-office-multi-year-research-development-and-22

[63] G. Squadrito, G. Maggio, E. Passalacqua, F. Lufrano, and A. Patti, "An empirical equation for polymer electrolyte fuel cell (PEFC) behaviour," Journal of Applied Electrochemistry, vol. 29, pp. 14491455, December 011999.

[64] R. F. Mann, J. C. Amphlett, M. A. I. Hooper, H. M. Jensen, B. A. Peppley, and P. R. Roberge, "Development and application of a generalised steady-state electrochemical model for a PEM fuel cell," Journal of Power Sources, vol. 86, pp. 173-180, 2000/03/01/ 2000.

[65] A. Saadi, M. Becherif, A. Aboubou, and M. Y. Ayad, "Comparison of proton exchange membrane fuel cell static models," Renewable Energy, vol. 56, pp. 64-71, 2013.

[66] S. M. Salamati, C. S. Huang, B. Balagopal, and M. Chow, "Experimental battery monitoring system design for electric vehicle applications," in 2018 IEEE International Conference on Industrial Electronics for Sustainable Energy Systems (IESES), 2018, pp. 3843.

[67] B. Zine, K. Marouani, M. Becherif, and S. Yahmedi, "Estimation of Battery Soc for Hybrid Electric Vehicle using Coulomb Counting Method," in International Journal of Emerging Electric Power Systems vol. 19, ed, 2018.

[68] N. Sulaiman, M. A. Hannan, A. Mohamed, E. H. Majlan, and W. R. Wan Daud, "A review on energy management system for fuel cell hybrid electric vehicle: Issues and challenges," Renewable and Sustainable Energy Reviews, vol. 52, pp. 802-814, 2015.

[69] D. Fares, R. Chedid, S. Karaki, R. Jabr, F. Panik, H. Gabele, et al., "Optimal power allocation for a FCHV based on linear programming and PID controller," International Journal of Hydrogen Energy, vol. 39, pp. 21724-21738, 2014/12/12/ 2014.

[70] T. B. N. Shidore, M. Duoba, H. Lohse-Busch, P. Sharer, "PHEV 'All electric range' and fuel economy in charge sustaining mode for low SOC operation of the Li-ion battery using battery HIL," in Proc. 23rd Int. Electric Vehicle Symp., 2007.

[71] M.-J. Kim and H. Peng, "Power management and design optimization of fuel cell/battery hybrid vehicles," Journal of Power Sources, vol. 165, pp. 819-832, 2007/03/20/ 2007.

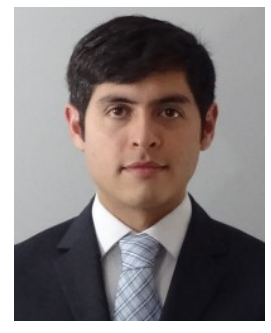

Alvaro Macias F. (S'17) was born in Mexico City, in 1992. He received the B.S. degree in mechatronics engineering from Tec de Monterrey, Guadalajara, Mexico, in 2015 and the M.S. degree in electrical engineering from Université du Québec à TroisRivières, Canada, in 2018. He is currently pursuing the $\mathrm{Ph} . \mathrm{D}$. degree in electrical engineering at Université du Québec à Trois-Rivières, Canada. From 2015 to 2016, he worked as Research and Development in the Centro de Investigación y de Estudios Avanzados del Instituto Politécnico Nacional, Mexico. His current research interest includes the development of energy management strategies for fuel cell systems, passive and active system configuration, and fuel cell modeling.

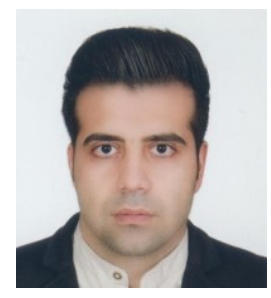

Mohsen Kandidayeni ( $\mathrm{S}^{\prime} 18$ ) is currently a $\mathrm{PhD}$ student at Université du Québec à Trois-Rivières (UQTR), working on energy-related topics such as Hybrid Electric Vehicles, Fuel cell systems, Energy management, Multiphysics systems, Modeling and Control. He graduated from Arak University with a master's degree in Mechatronics. His research interests are in the area of Renewable Energy, Fuel Cell, Transportation, Intelligent Transport Systems, Vehicular Systems Control, Hybrid Electric and Electric Vehicles.

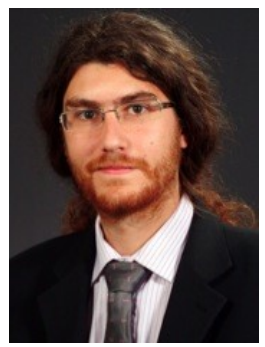

Loïc Boulon (M'10, SM'16) received the master's degree in electrical and automatic control engineering from the University of Lille (France), in 2006. Then, he obtained a PhD in electrical engineering from University of Franche-Comté (France). Since 2010, he is a professor at Université du Québec à TroisRivières (Canada) and he works at the Hydrogen Research Institute (Full Professor since 2016). His work deals with modeling, control and energy management of multiphysics systems. His research interests include hybrid electric vehicles, energy and power sources (especially battery in cold weather operation), and fuel cell systems. He has published more than 100 scientific papers in peer-reviewed international journals and international conferences.

In 2015, Loïc Boulon was general chair of the IEEE-Vehicular Power and Propulsion Conference in Montréal (QC, Canada). Prof. Loïc Boulon is VPMotor Vehicles of the IEEE Vehicular Technology Society and he is the holder of the Canada Research Chair in Energy Sources for the Vehicles of the future.

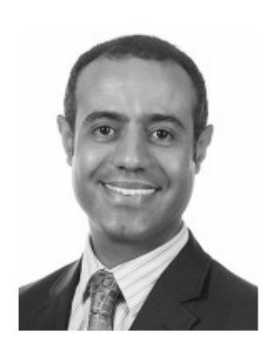

Hicham Chaoui (S'01-M'12-SM'13) received the $\mathrm{Ph} . \mathrm{D}$. degree in electrical engineering (with honors) from the University of Quebec, Trois-Rivières, QC, Canada, in 2012. His career has spanned both academia and industry in the field of control and energy systems. From 2007 to 2014, he held various engineering and management positions in the Canadian industry. From 2014 to 2016, he was an Assistant Professor at Tennessee Technological University, Cookeville, TN, USA. Since then, he has been a Faculty Member at Carleton University, Ottawa, ON, Canada. His research interests include adaptive and nonlinear control theory, intelligent control, robotics, electric motor drives, and energy conversion and storage systems. His scholarly work has produced more than 100 journal and conference publications. Dr. Chaoui was a recipient of the Best Thesis Award and the Governor General of Canada Gold Medal Award. He is a senior member of IEEE and a registered professional engineer in the province of Ontario. He is also an Associate Editor of IEEE Transactions on Vehicular Technology. 